\title{
DESCOLONIZACIÓN Y MIGRACIONES DESDE EL ÁFRICA ESPAÑOLA (1956-1975)*
}

\author{
Vicente Gozálvez Pérez
}

\section{RESUMEN}

Los territorios africanos que estuvieron bajo administración española son el Protectorado Español de Marruecos (hasta 1956), Guinea Ecuatorial (hasta 1968), Ifni (incorporado a Marruecos en 1969) y Sáhara Español (hasta 1975); en el momento de la descolonización censaban una población española total de más de 132.000 personas. Para cada uno de estos territorios se estudia: a) el volumen, características geodemográficas y situación económica y social de la población española residente, en los años anteriores a la descolonización; b) los nativos auxiliares de la Administración española; c) los flujos de repatriación de los españoles con motivo de la descolonización; d) indemnizaciones a los repatriados. El estudio se completa con un inventario de las principales fuentes de investigación.

\section{RÉSUMÉ}

Les territoires africains auparavant sous l'administration espagnole sont le Protectorat Espagnol du Maroc (jusqu'en 1956), Guinée Equatoriale (jusqu'en 1968), Ifni (incorporé au Maroc en 1969) et Sahara Espagnol (jusqu'en 1975); au moment de la décolonisation on recensait dans ces territorires une population espagnole totale de plus de 132.000 personnes. Pour chacun de ces territoires on étudie: a) le volume, les caractéristiques géodémographiques et la situation économique et sociale de la population espagnole résidente, pendant les années précédentes à la décolonisation; b) les indigènes auxiliaires de l'Administration espagnole; c) les flux de rapatriement des espagnols à cause de la décolonisation, d) les indemnisations aux rapatriés. L'étude se complète avec un inventaire des principales sources d'information.

Los territorios africanos bajo administración española tienen una importancia colonial menor, tanto en sus aspectos demográfico-económicos, como por su corto período como

* Este trabajo se ha realizado dentro del equipo internacional de investigación «Migrations induites par les décolonisations», dirigido por los profesores Jean-Louis Miège, de la Universidad de Provence (Francia), y Pieter Emmer, de la Universidad de Leiden (Holanda), y patrocinado por la European Science Foundation (Strasbourg). 
tales colonias. El Protectorado de Marruecos establecido en 1912 accede a su plena soberanía el 7-IV-1956; en Guinea Ecuatorial, la isla de Fernando Poo queda bajo administración española desde 1777, mientras la parte continental lo está desde 1900, y ambos territorios proclaman su independencia como República de Guinea Ecuatorial el 12-X1968. Las zonas desérticas de Ifni y Sáhara Español sólo muy recientemente censan un volumen apreciable de españoles, cuyo brusco incremento deriva, en parte, de la independencia marroquí: Ifni, ocupado de facto por los españoles en 1934, se incorpora a Marruecos el 13-V-1969, mientras en el Sáhara finaliza la administración española con la Ley de Descolonización de 19-XI-1975, después de los acuerdos tripartitos de Madrid de 14-XI1975, por los que el territorio español de Sáhara se cedía a Mauritania y Marruecos.

En el momento de su independencia, la población europea - casi exclusivamente española - residente en estas colonias daba las siguientes cifras: a 31-XII-1955 la población española en el Proctectorado español de Marruecos era «estimada» en 90.939 habitantes, que representaban el 9,4\% respecto a los nativos — 963.620-; a los indicados habría que añadir otros 25.698 españoles en el Marruecos bajo administración francesa (censo de 15-IV-1951) y más de 21.500 en Tánger ${ }^{1}$. En Guinea Ecuatorial los europeos censados en 1966 eran 9.137, es decir, un 3,7\% respecto a los 248.940 nativos de color. En Ifni los europeos sumaban 11.984 en 1967 (incluidos militares de tropa), equivalentes al 28\% de los 41.663 nativos estimados para 1964. Finalmente, en el Sáhara Español en 1974 residían 20.126 españoles (excluidos militares de tropa), cifra que alcanzaba el 27\% de los 74.902 nativos censados. En suma, las principales colonias de españoles contabilizados en África entre 1950 y 1975 dan un total de 215.384 habitantes*; en 1990, según el Registro de Matrícula Consular sumaban 12.664 españoles, de los cuáles 8.460 en Marruecos y 892 en Guinea Ecuatorial2 .

\section{La presencia española en el Sáhara}

El territorio del Sáhara Español $\left(280.000 \mathrm{~km}^{2}\right)$ quedaba delimitado en los tratados hispano-franceses de 1900, 1904 y 1912, aunque con presencia española mínima, dadas las características económicas y humanas de esta zona desértica; la población española en la colonia sólo aumenta a partir de 1960, en buena parte a resultas de la independencia del Protectorado español de Marruecos (1956), por la retrocesión de Ifni (1969), y más tardía-

* Mi agradecimiento a los responsables del Archivo General de la Administración y del Archivo Central del Ministerio de Relaciones con las Cortes, en especial a D. José Luis La Torre Merino, D. Ignacio Ruiz Alcaín y $\mathrm{D}^{\mathrm{a}}$ Pilar Casado, que atendieron al máximo de sus posibilidades mi petición de accesibilidad a fondos documentales de África. También quiero destacar la ayuda documental recibida de D. José Ramón Manjón, de la Dirección General de Migraciones, y de D. Fernando Álvarez, bibliotecario de esta misma institución. De modo especial agradezco a mi colega Mikel de Epalza que me brindara el entorno científico que ha hecho posible realizar esta investigación.

1 La población española en la ciudad de Tánger era de 15.486 habitantes en noviembre de 1941 (Ministerio de Trabajo, Dirección General de Estadística, Zona de Protectorado y de los territorios de soberanía de España en el norte de África. Anuario estadístico, 1944, p. 23) y más de 21.500 a mediados de los años 1950 , según artículos de Josef M. de Cerdán publicados en el diario El Alcázar, mayo 1961).

Por otra parte, en 1954 la colonia española en Argelia era de 36.000 personas, censo que había disminuido progresivamente desde los 144.328 que se registran en 1921. Vid. Bonmatí Antón, J.F., Españoles en el Magreb, siglos XIX y XX, Madrid, 1992, pp. 68 y 124.

2 Ministerio de Trabajo y Seguridad Social. Dirección General de Migraciones, Anuario de Migraciones, 1992, p. 21. 
Figura 1. Evolución de la población europea de hecho en el Sáhara español (1950-1974).

mente, por la explotación de fosfatos. En efecto, en 1950 los europeos censados en el Sáhara Español eran 1.340 y 1.710 en 1958, pero en 1960 su número ya alcanzaba 5.304, 16.648 en 1970 y 20.126 en 1974 (Vid. Cuadro I); las cifras anteriores incluyen a los militares profesionales, pero no a los de tropa.

Los datos demográficos referidos al Sáhara distinguen entre población nativa y población europea, o «raza blanca» en el caso del movimiento natural; no obstante, la práctica totalidad de los europeos son españoles, según se puede deducir de los diferentes contex$\operatorname{tos}^{3}$.

Los censos de población sobre el Sáhara Español siempre señalan una alta fiabilidad en sus datos de población europea, especialmente para la concentrada en los núcleos urbanos de El Aaiún y Villa Cisneros — 90 a 96\% del total entre 1967 y 1974—. Respecto a la población nativa la fiabilidad censal es cuestionada en medida directa a la proporción de nómadas, cuyo recuento se suple con frecuentes estimaciones; el Censo de 1967 estima que la mitad de la población nativa aún es nómada, aunque la sedentarización aumenta inducida por la Administración española: empleados y comerciantes en los núcleos principales, empleos en la construcción y las obras públicas ${ }^{4}$. Para el Censo de 1974, cuya publicación sólo recoge la población nativa, todos los comentarios señalan una elevada fiabilidad, pues los medios utilizados en la recogida de datos mejoraron sustancialmente dadas sus finalidades $^{5}$ : establecer dos censos, uno electoral — referendum para la autodeterminación previsto para finales de $1974^{6}$ - y otro escolar; a ello se unió el aumento de la sedentarización provocado por un recrudecimiento de la sequía, que hace que los nativos se establezcan en torno a los lugares donde la administración española proporcionaba ayuda para personas y

3 Los 434 europeos nacidos en el extranjero que indica el Censo de 1967, según sus edades habría que identificarlos con españoles nacidos en el antiguo Protectorado español de Marruecos (antes de 1956).

La no utilización del término «españoles» en las fuentes estadísticas parece relacionada con la condición de españoles que habría que atribuir a los nativos una vez que, en 1958 y 1959, son declaradas «provincias» las colonias de Sáhara, Ifni, Fernando Poo y Río Muni.

4 Provincia de Sáhara. Censo de Población, 1967, p. 7.

5 La recogida de datos fue realizada por 30 agentes censales nativos, bilingües, que utilizaron 10 vehículos Land Rover, y un helicóptero en las zonas de difícil acceso.

6 Archivo General de la Administración (AGA), Caja AF-D-486. 
ganado 7 . El censo de 1974 señala 74.902 habitantes, de los que 73.494 son saharauis, 548 extranjeros africanos, especialmente mauritanos, y 857 residentes africanos 8 .

Como en el resto de colonias de España en África, la población europea en el Sáhara Español se concentra en los núcleos urbanos, fundamentalmente en la capital El Aaiún, cuyo crecimiento es fulgurante: 379 españoles en 1950, 2.607 en 1960, 12.290 en 1970 y 15.626 en 1974 (Vid. Cuadro I), equivalentes al 78\% del total de europeos censados en esta colonia; si en 1950 había en El Aaiún 474 varones por 100 mujeres, en 1974 eran 185. La segunda ciudad, Villa Cisneros, es de crecimiento más modesto, censa 312 europeos en 1950 y 3.709 en 1974, y con sex ratio mucho más equilibrada -107 en 1950, 109 en 1974-. Estos dos núcleos urbanos concentran en 1974 el $96 \%$ de los europeos censados en el Sáhara Español, que a su vez constituían más de la mitad de la población total en cada una de las dos ciudades. En las otras concentraciones de población del Sáhara Español, Güera y Smara, la presencia europea era casi testimonial, 249 y 170 europeos, respectivamente. La fortísima concentración urbana de los españoles, su alta tasa de masculinidad, así como su elevada proporción de personal administrativo y militar, son características que, en su momento, facilitarán una evacuación rápida y total.

\section{Las características geodemográficas}

De los 9.395 europeos censados en $1967^{9}$, más de una tercera parte - 3.317- había nacido en las Islas Canarias, territorio metropolitano más cercano a la colonia; la distribución por edades de esta población canaria en Sáhara señala que tal origen es debido a la emigración de adultos-jóvenes (20-39 años) desde las islas, así como al uso de las clínicas de maternidad del archipiélago por parte de las mujeres españolas residentes en Sáhara. El contingente nacido en el Sáhara es el menos voluminoso - 6\% del total de los europeos, y casi todos tienen menos de 10 años de edad, lo que es acorde con el tardío y brusco incremento de los españoles en este territorio.

La sex ratio de la población europea siempre es anormalmente elevada, con 2-3 varones por cada mujer; el censo de 1967 apunta la posibilidad de que en 1950 y 1960 los datos incluyan a parte de los militares de tropa, sobre todo en El Aaiún, que alcanza sex ratio de 474 en 1950 y 432 en 1960; sin embargo, tales desequilibrios entre sexos pueden ser debidos al acelerado y peculiar proceso de llegada de europeos, pues las mujeres aumentan menos y más suavemente que los varones. El carácter de colonia administrativo-militar formada bruscamente queda evidenciado en la pirámide de edades de 1967: la sex ratio media de 130 es superada por todos los grupos de edad entre 25 y 60 años, a lo que se añade una acusada soltería entre los varones de 25 a 40 años de edad.

Las cifras de nacimientos responden a la evolución del contingente poblacional, es decir, tanto las cifras de habitantes como las de nacimientos de 1974 multiplican por 15 a las registradas en 1950 (Vid. cuadros). Las tasas de natalidad son muy inferiores a las medias nacionales debido a los desequilibrios en la sex ratio; la excepción se da en 1967, cuando se registra un mayor equilibrio de sexos - 130 varones por 100 mujeres - y la natalidad alcanza 30,7 por 1.000, dada la acusada juventud demográfica: el $41 \%$ de la población tiene entre 20 y 39 años de edad.

7 AGA, Caja AF-D-486. Una Memoria del Gobierno del Sáhara de 1975 señala la rápida sedentarización de los saharauis, que llega al 82\% del total, según datos del Censo de 1974, AGA, Caja AF-D-527.

8 Los «residentes» son africanos autorizados a residir en la colonia por períodos de dos años, en su mayoría son mauritanos y marroquíes, AGA, Caja AF-D-527.

9 El Censo del Sáhara de 1967 es el único que publica datos estructurales de la población europea. 
FIGURA 2. Año 1967. Estructura por edad y sexo de la población europea de hecho en el Sáhara español (excluidos militares de tropa).

FIGURA 3. Tasas de natalidad y mortalidad de la población europea en el Sáhara español (1950-1974).

2. La situación económica y social

Según el censo de 1967, la tasa de actividad de los europeos es de 35,9\% (próxima a la media de España), aunque con fuertes diferencias entre sexos, 58,8\% en los varones y sólo $6,3 \%$ en las mujeres. La distribución de activos por sectores económicos es la que sigue:

\begin{tabular}{|lrr|}
\hline & Número & $\%$ \\
\hline Sector I & 210 & 6,2 \\
Sector II & 574 & 17,2 \\
Sector III & 2.436 & 72,3 \\
No clasificable & 146 & 4,3 \\
\hline
\end{tabular}

Dentro del sector secundario, el grupo más numeroso es el dedicado a la construcción, con 222 obreros, a los que se puede agregar parte de los 65 carpinteros; los «trabajadores de los metales» forman el segundo grupo con 183 activos; «minas y canteras» en estas fechas sólo contabilizan 4 empleados. 
Cuadro I

SÁHARA ESPAÑOL. POBLACIÓN EUROPEA DE HECHO (1950-1974)

\begin{tabular}{|crrrrrr|}
\hline & $\mathbf{1 9 5 0}$ & $\mathbf{1 9 5 8}$ & $\mathbf{1 9 6 0}$ & $\mathbf{1 9 6 7}$ & $\mathbf{1 9 7 0}$ & $\mathbf{1 9 7 4}$ \\
\hline Total & 1.320 & 1.710 & 5.304 & 9.395 & 16.648 & 20.126 \\
Varones & 951 & & 4.087 & 5.316 & 11.239 & 12.702 \\
Mujeres & 384 & & 1.217 & 4.079 & 5.409 & 7.424 \\
& & & & & & \\
El Aaiún & 379 & 889 & 2.607 & 5.842 & 12.290 & 15.626 \\
Varones & 313 & & 2.117 & 3.305 & 8.732 & 10.137 \\
Mujeres & 66 & & 490 & 2.537 & 3.558 & 5.489 \\
& & & & & & \\
Villa Cisneros & 312 & 776 & 629 & 3.090 & 2.722 & 3.709 \\
Varones & 161 & & 305 & 1.680 & 2.141 & 1.933 \\
Mujeres & 151 & & 324 & 1.410 & 1.581 & 1.776 \\
& & & & & & \\
Smara & & & & 214 & 352 & 170 \\
Varones & & & & 135 & 203 & 122 \\
Mujeres & & & & 79 & 149 & 48 \\
Güera & 63 & 55 & & 249 & 284 & 249 \\
Varones & 49 & & & 177 & 163 & 149 \\
Mujeres & 14 & & & 72 & 121 & 100 \\
Resto Provincia & $586 *$ & & $2.068 *$ & & & $372 * *$ \\
Varones & 428 & & 1.665 & & & 362 \\
Mujeres & 158 & & 403 & & & 11 \\
\hline
\end{tabular}

* En el Norte del Sáhara.

**En Bu-Cráa (313) y distintos puestos (59).

Fuente: Para 1950, 1958, 1960 y 1970, INE, Anuario Estadístico de España. Para 1967, Gobierno General del Sáhara, Censo de Población, 1967. Para 1974, AGA, Cajas AF-D-527 y AF-D-486.

El voluminoso sector terciario evidencia el carácter administrativo-militar de esta comunidad, pues casi la mitad - 1.111 — son militares profesionales, seguidos por los administrativos con 401, y casi a partes iguales los profesionales y técnicos (que incluyen a enseñantes y sanitarios) - 291-y los dedicados a transportes y comunicaciones - 276-, actividades vitales para este tipo de asentamientos.

\section{Los indígenas auxiliares}

La estructura profesional de los saharauis queda recogida en los censos de 1967 y 1974 ; pese a que sólo median siete años entre ambos, hay un cambio drástico en el empleo, explicado por el tardío y brusco incremento de la presencia española - 9.395 europeos en 


\begin{tabular}{|cccc|}
\hline Año & Nacimientos & Defunciones & Matrimonios \\
\hline 1950 & 20 & 9 & 2 \\
1951 & 23 & 9 & 2 \\
1952 & 24 & 3 & 1 \\
1953 & 19 & 6 & 2 \\
1954 & 25 & 5 & 3 \\
1955 & 14 & 2 & 3 \\
1956 & 12 & 2 & 3 \\
1957 & 19 & 5 & 4 \\
1958 & 33 & 26 & 7 \\
1959 & 31 & 2 & 5 \\
1960 & 52 & 36 & 10 \\
1961 & 78 & 43 & 8 \\
1962 & 101 & 40 & 22 \\
1963 & 163 & 61 & 37 \\
1964 & 173 & 49 & 30 \\
1965 & 240 & 33 & 38 \\
1966 & 243 & 37 & 34 \\
1967 & 324 & 49 & 48 \\
1968 & 298 & 49 & 67 \\
1969 & 256 & 45 & 43 \\
1970 & 307 & 29 & 80 \\
1971 & 250 & 50 & 67 \\
1972 & 258 & 38 & 71 \\
1973 & - & & \\
1974 & 294 & & \\
& & 30 & \\
\hline
\end{tabular}

Fuente: INE, Anuario Estadístico de España; Dirección General de Plazas y Provincias Africanas, Resumen Estadístico del África Española; id., Resumen Estadístico del Sáhara Español (año 1969).

1967, 20.126 en 1974 - y por el incremento de la sedentarización de los nativos-50\% y $82 \%$ del total, respectivamente-.

Frente a un escaso incremento en los empleos tradicionales como ganaderos, pescadores, sastres u «orfebres y asimilados», los empleos vinculados a la Administración española aumentan espectacularmente, tanto en el sector público como en el privado. De hecho, el censo de 1974 señala que los ganaderos son personas mayores, mientras que los peones (de ellos un elevado número trabaja en la construcción de carreteras), militares y conductores son jóvenes ${ }^{10}$. El que este cambio en la estructura del empleo se produzca en vísperas de la descolonización, sin duda repercute en una escasa vinculación de esta población activa con

10 Gobierno General del Sáhara, Censo de Población, 1974, pp. 61 y 77. 
SAHARA ESPAÑOL. POBLACIÓN NATIVA CLASIFICADA SEGÚN PROFESIONES, AÑN 1967 Y 1974

\begin{tabular}{|lrr|}
\hline Profesión & 1967 & 1974 \\
\hline Agricultores y Ganaderos & 6.176 & 7.973 \\
Pescadores & 160 & 148 \\
Orfebres y asimilados & 105 & 107 \\
Confección & 11 & 15 \\
Construcción & 3.957 & 5.424 \\
Obreros especializados & - & 353 \\
Industria alimentación & 59 & 329 \\
Comercio & 444 & 959 \\
Funcionarios Administración Pública & 337 & $?$ \\
Subalternos Administración Pública & 112 & 320 \\
Sanidad & 51 & 119 \\
Profesores & 23 & 139 \\
Militares (sin graduación) & 762 & 1.341 \\
Empleados oficina y subalternos sector privado & 112 & 320 \\
Servicios & 69 & 142 \\
Conductores de vehículos & 113 & 705 \\
Chejs y maestros Koram & 225 & 287 \\
\hline TOTAL & 12.716 & 18.681 \\
\hline Tasa de actividad (\%) & 27,1 & 25,2 \\
\hline
\end{tabular}

Fuente: Gobierno General del Sáhara, Censos de Población de la provincia de Sáhara, años 1967 y 1974.

la metrópoli, y por tanto sin consecuencias de expatriación a España al finalizar la Administración española en Sáhara. Por contra la sustitución de España por la administración marroquí y mauritana — después sólo marroquí-, dará origen a una considerable diáspora saharaui, aunque fundamentalmente concentrada hacia la vecina Argelia.

Los militares (sin graduación) constituyen uno de los grupos nativos auxiliares de la Administración española más importantes, 762 en 1967 y 1.341 en 1974 (Vid. Cuadro); el empleo en la Administración también incluye a funcionarios civiles, personal subalterno (112 en 1967, 320 en 1974), docentes (23 en 1967, 139 en 1974) y sanitarios (51 y 119, respectivamente). Asimismo, es exponente de la llegada tardía y rápida de los españoles, el crecimiento del empleo nativo en la empresa privada, como se observa en el cuadro adjunto para los empleados de oficina y subalternos, los dedicados al comercio, los conductores de vehículos, los obreros de la construcción (incluidas obras públicas) y los de la industria de la alimentación.

En julio de 1969 la propuesta de plantilla orgánica del Gobierno General del Sáhara incluía 2.690 empleados, de los que 634 eran nativos, con la siguiente distribución: 180 ordenanzas, 27 intérpretes, 35 administrativos, 60 profesores de religión islámica, 39 
especialistas en justicia «coránica», 17 escribientes de árabe, 64 sanitarios y 212 chiuj o notables ${ }^{11}$.

Un informe de la Administración del Sáhara español del año $1975^{12}$ evalúa en 13.000 el número de trabajadores saharauis empleados en 1974 en el sector público y privado dependiente de empresas españolas, de los que 8.000 serían peones de la construcción y obras públicas, 2.500 trabajadores especializados, y 800 funcionarios: como mayores empresas por su empleo cita al Gobierno General del Sáhara, Fosfatos Bucráa S.A. ${ }^{13}$ y Construcciones, Cubiertas y Tejados S.A.

La escasa vinculación de los saharauis con la metrópoli, en parte viene condicionada por el alto porcentaje de nómadas hasta fechas cercanas a la descolonización y, simultáneamente, por la escasa presencia de españoles hasta los años sesenta; como cifras que reflejan este hecho, se pueden citar los escasos saharauis residentes en la metrópoli en 1974: 174 en la península y 62 en Canarias, mientras en Marruecos había 348, en Mauritania 1.300 y otros 13 en distintos países europeos ${ }^{14}$; de los saharauis residentes en la metrópoli, en 1975 había 56 estudiantes universitarios ${ }^{15}$. Por otra parte, entre 1976 y 1977 parece que sólo se habían hecho 88 informes sobre saharauis peticionarios de la nacionalidad española ${ }^{16}$. Las cifras anteriores contrastan con las de refugiados saharauis en Tinduf, en el sur de Argelia, que huyen con motivo de la ocupación del Sáhara Español por Marruecos y Mauritania; en 1977, con motivo de una reunión de comisionados del Alto Comisariado de las Naciones Unidas para ayuda a estos refugiados y con representantes del Gobierno español, se estima en unos 50.000 los saharauis refugiados, aunque las autoridades argelinas señalan $150.000^{17}$.

\section{La repatriación de los españoles residentes en el Sáhara}

Dadas las características del entorno, la población residente en el Sáhara presentaba una notable inestabilidad, tal y como señala en 1975 una Memoria sobre el Sáhara elaborada por la Administración: «.. alguna [población europea] reside en el Territorio por períodos relativamente breves, con frecuentes relevos. Entre ellos los funcionarios civiles y militares, técnicos y trabajadores temporeros. Otros como los comerciantes y trabajadores fijos permanecen en el Territorio por períodos más largos, pero pocos se arraigan de modo definitivo». Si a esta valoración se añade las especiales circunstancias en las que finaliza la

11 AGA, Caja AF-D-560.

12 AGA, Caja AF-D-527.

13 Fosfatos de Bu-Cráa, S.A. era una empresa estatal del Instituto Nacional de Industria. Comenzó su actividad, en fase experimental, en 1973, aunque fue constituida el 4 de julio 1962 en cumplimiento del Decreto 1304/1962, de 7 de junio, inicialmente con la denominación «Empresa Nacional Minera del Sáhara, S.A.» y desde 22 de mayo 1969 bajo la denominación citada al principio (AGA, Caja AF-D-517, «Reglamento de Régimen interior de Fos Bucráa», de fecha 10-XII-1975). A partir de agosto de 1974 inició la fase industrial de explotación y durante ese año se embarcaron 2,1 millones de Tm de fosfatos. El mineral se llevaba a la planta de concentración en una cinta transportadora de $98 \mathrm{~km}$ de longitud, capaz de transportar $2.000 \mathrm{tm} /$ hora. El embarque de los fosfatos se realizaba en un pantalán de $3.100 \mathrm{~m}$, que permitía la entrada de buques de hasta $100.000 \mathrm{Tm}$. La inversión en Fosbucráa ascendía en 1974 a 24.000 millones de pesetas (AGA, Caja AF-D-527). En julio de 1974 se hacían las siguientes previsiones de personal para la empresa: para una producción de 3 millones de tm/año de fosfato, 1.509 empleados; para 6 millones (previstas para el año 1976), 1.880 empleos; para 10 millones (previstas para 1980), 2.520 empleos; el 40\% de la plantilla sería cubierto con personal nativo (AGA, Caja AF-D487). De hecho, a finales de 1975 el Centro Minero de Fosbucráa tenía una plantilla de 2.571 trabajadores (AGA, Caja AF-D-517, «Reglamento de régimen interior de Fos-Bucráa», Anexo 12).

14 Censo de población de 1974, p. 52.

15 AGA, Caja AF-D-527.

16 AGA, Caja AF-D-531 y AGA, Caja AF-D-886.

17 AGA, Caja AF-D-527. 
Administración española en el Sáhara, es comprensible una evacuación de la población española prácticamente total. El 14-XI-1975 se firmaba en Madrid el acuerdo tripartito por el que España cedía la Administración del Sáhara a Marruecos y Mauritania, y establecía de inmediato una administración temporal en la que participarían los dos países africanos; la retirada de la Administración española del Sáhara se realizaría antes del 28 de febrero de $1976^{19}$. El paso siguiente fue la publicación de la Ley de 19-XI-1975 sobre descolonización del Sáhara, votada el día anterior en las Cortes ${ }^{20}$.

El 3 de diciembre de $1975^{21}$ se informa que ningún funcionario civil tiene intención de permanecer en Villa Cisneros cuando España retire su presencia militar, pues el orden público se deterioraba progresivamente, debido a los desórdenes que ya se registraban durante el período de Administración transitoria; de hecho, el 27-I-1976 la colonia española en Villa Cisneros se había reducido a 124 personas. Esta evacuación sin duda estaba prevista, pues las autoridades de Las Palmas, en octubre de 1975, preveían la llegada al archipiélago de 10.000 refugiados $^{22}$, teniendo en cuenta que una parte de los residentes no había vuelto al Sáhara después de sus vacaciones estivales.

A finales de abril de 1976 el número de españoles residentes en el Sáhara se había reducido a 139, de los que 88 en El Aaiún y 51 en Villa Cisneros, aunque la relación no incluye a los que trabajan por cuenta propia, por no considerarlos residentes estables ${ }^{23}$. A mediados de 1978, el censo electoral de los españoles residentes en el Sáhara era de 193, de los que 93 trabajaban en la empresa Fos-Bucráa, aunque estos últimos eran sólo una «parte mínima» pues otro documento de fechas próximas señala unos 400 españoles en la citada empresa, mientras a mediados de febrero de 1976 eran unos 600. La vinculación de la población de las Islas Canarias con el Sáhara queda patente una vez más: de los 193 residentes indicados, 101 habían nacido en Canarias, y algunos en Marruecos ${ }^{24}$.

\subsection{La financiación de la descolonización}

El 7-XI-1975 el Consejo de Ministros de España autorizó un crédito extraordinario de 1.000 millones de pesetas para culminar el proceso de descolonización del Sáhara ${ }^{25}$, con la siguiente distribución de gastos: 1) 305 millones de pesetas para el pago de indemnizaciones por repatriación a funcionarios civiles y militares, y a trabajadores al servicio del gobierno del Sáhara; 2) 62'9 millones para pago de dietas, pasajes y traslado de mobiliaro; 3) 195'2 millones para bolsas de viaje y auxilios en la evacuación de personal civil; 4) 436' 8 millones para gastos varios. En 1975 se calcula en 1.092 el número de funcionarios civiles y militares a indemnizar por repatriación, a los que acompañarían 3.281 familiares $^{26}$.

18 AGA, Caja AF-D-527.

19 AGA, Caja AF-D-527.

20 Presidencia del Gobierno. Secretaría General Técnica, La descolonización del Sáhara, Madrid, 1975, 61 pp.

21 AGA, Caja AF-D-527.

22 AGA, Caja AF-D-527.

23 AGA, Caja AF-D-531.

24 AGA, Caja AF-D-531.

25 AGA, Caja AF-D-816. A efectos comparativos con los gastos de indemnización por descolonización cubiertos por el Estado, la Hacienda Pública de la provincia de Sáhara tenía unos ingresos de 1.597 millones de pesetas en 1973, y de 2.472 millones en 1974, de los que el 69\% eran subvención estatal (AGA, Caja AF-D-527).

26 AGA, Caja AF-D-506. 
Por otra parte, el Consejo de Ministros de 18-II-1977 acordó un crédito extraordinario de 1.100 millones de pesetas —más un suplemento de crédito de 350 millones - para indemnizaciones a comerciantes e industriales evacuados del Sáhara ${ }^{27}$; en enero de 1979 se contabilizan 599 expedientes de solicitud de indemnización de este grupo empresarial ${ }^{28}$, entre los que se encontraban 5 saharauis comerciantes. Una Comisión ad hoc se encargó de tales trámites, y resolvió favorablemente la mayoría de ellos.

\section{La presencia española en Ifni}

La cesión del territorio de Ifni a España fue acordada con el Sultán de Marruecos en $1860{ }^{29}$, pero la ocupación española de hecho se realizó a partir de 1934; la retrocesión de este territorio al Reino de Marruecos tuvo lugar el 13 de mayo de 1969.

El reducido territorio de Ifni $\left(1.500 \mathrm{~km}^{2}\right)$, localizado en la costa atlántica del sur de Marruecos, llegó a tener una población española relativamente notable y casi totalmente concentrada en su capital Sidi Ifni, donde los europeos doblaban a los nativos.

Las cifras censales muestran un fuerte y rápido crecimiento de la población europea en los años anteriores a 1960 - 3.500 habitantes en 1956, 8.219 en 1960 (Vid. Cuadro IV) , sin duda relacionado con la independencia del Protectorado español de Marruecos (1956); en su mayoría son militares y funcionarios ${ }^{30}$. La disparatada sex ratio que se alcanza en 1960 (194 varones por 100 mujeres en 1950, 607 en 1960), se explica tanto por la concentración de llegadas como, sobre todo, porque las cifras censales parece que incluyen a la población de tropa.

En efecto, las fuentes sobre la población europea de Ifni - a diferencia de lo que indican en el caso del Sáhara- parecen contabilizar de forma conjunta a los militares de tropa con el resto, es decir, con la población civil y los funcionarios militares. Así, un «Informe sobre la provincia de Ifni» fechado en Sidi Ifni el 26-VIII-1968, realizado por el Gobierno General de aquella provincia ${ }^{31}$, señala como población europea la siguiente:

1) Militares profesionales 767 (encuadrados en unidades del Ejército)

Sus esposas

Sus hijos

2) Funcionarios militares

101

(no encuadrados en unidades del Ejército)

Sus esposas

Sus hijos

234

3) Personal de tropa

6.167

27 AGA, Caja AF-D-816.

28 AGA, Caja AF-D-886.

29 «Tratado de paz y amistad celebrado entre España y Marruecos en Tetuán el 26 de Abril de 1860», en su art. 8 dice «S.M. Marroquí se obliga a conceder a perpetuidad a S.M. Católica en la costa del Océano junto a Santa Cruz la pequeña el terreno suficiente para la formación de un establecimiento de pesquería como el que España tuvo allí antiguamente». AGA, Caja AF-M-181, exp. nº 2.

30 AGA, Caja AF-S-165.

31 AGA, Caja AF-S-239.

32 Este subtotal es la suma de los que integran las diversas unidades militares indicadas en el Informe; sin embargo, el mismo documento indica como subtotal 7.967 ó 1.800 militares más. Por otra parte, el mismo Informe señala que las tropas actuales en filas en Ifni están formadas por 4 llamamientos de 1.700 hombres, es decir, un total de 6.800 . 
Figura 4. Evolución de la población europea de hecho en Ifni (1950-1967).

4) Funcionarios civiles 108

Sus esposas $\quad 100$

$\begin{array}{lr}\text { Sus hijos } & 202\end{array}$

5) Otro personal europeo 178

Sus esposas $\quad 131$

$\begin{array}{ll}\text { Sus hijos } & 300\end{array}$

$\begin{array}{ll}\text { TOTAL } & 10.205 \quad 33\end{array}$

Así pues la cifra total, tropa incluida, coincide con la censal de 1967 ofrecida en el cuadro IV.

Cuadro IV

IFNI. POBLACIÓN EUROPEA DE HECHO

\begin{tabular}{|crrrrrrrrr|r|}
\hline & $\mathbf{1 9 5 0}$ & $\mathbf{1 9 5 4}$ & $\mathbf{1 9 5 5}$ & $\mathbf{1 9 5 6}$ & $\mathbf{1 9 5 9}$ & $\mathbf{1 9 6 0}$ & $\mathbf{1 9 6 2}$ & $\mathbf{1 9 6 4}$ & $\mathbf{1 9 6 6}$ & $\mathbf{1 9 6 7}$ \\
\hline Total & 2.267 & 2.995 & 3.318 & 3.500 & 4.039 & 8.219 & 8.779 & 9.354 & & \\
Varones 1.497 & & & & 3.139 & 7.057 & 7.175 & 7.609 & & \\
Mujeres & 770 & & & & 900 & 1.162 & 1.604 & 1.745 & & \\
Sidi Ifni & 2.197 & & & 3.177 & & 8.201 & 8.756 & 9.340 & 10.234 & 11.984 \\
Varones & 1.453 & & & 2.241 & & 7.043 & & & 8.447 & 9.885 \\
Mujeres & 744 & & & 936 & & 1.158 & & & 1.787 & 2.099 \\
\hline
\end{tabular}

Fuente: Para 1950 a 1956 y 1960, INE, Anuario Estadístico de España.

Para 1959 y 1961 a 1964, Dirección General de Plazas y Provincias Africanas, Resumen Estadístico del África Española.

Para 1966, AGA, Caja AF-S-71.

Para 1967, AGA, Caja AF-S-239.

33 El total sería de 12.005 si se admite la suma de personal de tropa indicada en el Informe. 
La disparatada sex ratio que se deduce de las cifras sobre evolución de la población de Ifni, desaparece en los datos de 1968 si excluimos al personal de tropa: por cada 100 esposas hay 128 varones adultos, cifra similar a la sex ratio de 130 que ofrece el censo de población del Sáhara en 1967 (que excluye a la tropa).

La población censal de 1960 ofrecida por el Instituto Nacional de Estadística para las colonias africanas ${ }^{34}$, parece que ha sido calculada con una metodología distinta en el caso de Ifni, y que confirmaría la inclusión de los militares de tropa en la población censal de ese territorio:

\begin{tabular}{|lccccccc|}
\hline & \multicolumn{2}{c}{ Residentes presentes } & \multicolumn{2}{c}{ Transeúntes } & \multicolumn{2}{c|}{ Población de hecho } & \\
& Varones & Mujeres & Varones & Mujeres & Varones & Mujeres & Total \\
\hline Ifni & 2.189 & 1.116 & 4.868 & 46 & 7.057 & 1.162 & 8.219 \\
Sáhara & 3.296 & 1.217 & 791 & $\underline{4}$ & 4.087 & 1.127 & 5.304 \\
Guinea & 4.108 & 2.626 & 303 & 49 & 4.411 & 2.675 & 7.086 \\
\hline
\end{tabular}

Así, la elevada población transeúnte masculina en Ifni, podría hacer referencia a los militares de tropa, lo que no ocurre en las otras colonias.

\section{Las características geodemográficas}

La tardía incorporación del territorio de Ifni a la Administración española, y su carácter militar no estabilizado, reduce a mínimos los europeos nacidos en la colonia (Vid. Cuadro V). Antes de 1960 la tasa de natalidad es próxima a la media nacional —en torno a 20 por 1.000-; después de 1960 las cifras relativas quedan totalmente alteradas por la anomalía metodológica que parece se sigue al ofrecer la población censal de Ifni. No obstante, si sobre los datos de población ofrecidos para 1968 (Vid. supra) excluimos a los militares de tropa, la natalidad se elevaría a 29,2 por mil, tasa totalmente equiparable a la que tenía Sáhara en 1967, lo que induce a pensar, en consecuencia, en una estructura de edades similar en ambas colonias.

La información disponible no permite valorar la importancia de los matrimonios mixtos, en Ifni y Sáhara, entre europeos y nativos, aunque parecen inexistentes.

La independencia de Marruecos en 1956 — que no incluirá al territorio de Ifni hasta 1969- provocará la inestabilidad en esta colonia, iniciada con la agresión del llamado «Ejército de Liberación» el día 23 de noviembre de $1957^{35}$ lo que se traduce en la fuerte alteración de la secuencia de defunciones (Vid. Cuadro V).

\section{La situación económica y social}

Las estadísticas publicadas sobre Ifni no incluyen datos socio-económicos; la información utilizada se ha obtenido de los informes elaborados con motivo de su descolonización. La población europea de Ifni residía casi totalmente en su capital, Sidi Ifni, donde en 1967 los europeos eran 11.984 y 5.662 los nativos.

Como se ha indicado, en 1968 los activos masculinos incluían a 767 militares profesio-

34 INE, Anuario Estadístico de España.

35 AGA, Caja AF-S-239. 


\section{Cuadro V}

IFNI. MOVIMIENTO NATURAL DE LA POBLACIÓN EUROPEA

\begin{tabular}{|cccc|}
\hline Año & Nacimientos & Defunciones & Matrimonios \\
\hline 1950 & 45 & 15 & 5 \\
1951 & 43 & 9 & 10 \\
1952 & 44 & 7 & 8 \\
1953 & 67 & 4 & 7 \\
1954 & 56 & 6 & 13 \\
1955 & 63 & 10 & 11 \\
1956 & 52 & 5 & 5 \\
1957 & 64 & 70 & 7 \\
1958 & 73 & 81 & 9 \\
1959 & 60 & 19 & 11 \\
1960 & 84 & 14 & 9 \\
1961 & 90 & 18 & 14 \\
1962 & 75 & 9 & 6 \\
1963 & 89 & 17 & 17 \\
1964 & 724 & 9 \\
1965 & 80 & 12 & 13 \\
1966 & 112 & 9 & 17 \\
1967 & 124 & 8 & 12 \\
\hline
\end{tabular}

Fuente: INE, Anuario Estadístico de España.

Para 1968, AGA, Caja AF-D-656.

nales, 101 militares funcionarios, 108 funcionarios civiles y 178 que ejercían actividades diversas ${ }^{36}$. Estos últimos tenían la siguiente distribución profesional:

\begin{tabular}{|lrc|lrr|}
\hline & Total & $\%$ & & Total & $\%$ \\
\hline Hortelanos & 3 & 2 & Conductores & 25 & \\
Construcción & 15 & & Mecánicos & 14 & \\
Carpintería & 12 & & Comercio & 19 & \\
Industriales & 10 & & Hostelería & 13 & \\
Otros & 15 & \multirow{2}{*}{29} & Administrativos & 14 & \\
Total Sector II & 52 & & Otros & 25 & \\
& & & Total Sector III & 123 & 69 \\
\hline
\end{tabular}

Por otra parte, una relación de industrias y comercios de Ifni de 1966 totaliza 88 establecimientos $^{37}$, con un total de 151 empleados (nativos incluidos); los establecimientos más numerosos son: 15 mercerías, 12 talleres de confección para nativos, 10 zapaterías, 10 comercios de fotografía, 8 panaderías, 7 peluquerías de señora, 7 carpinterías, etc., es decir,

37 AGA, Caja AF-S-71. 
se trata de comercios e industrias para atender necesidades básicas; por número de trabajadores, la industria mayor era la «fábrica de electricidad» con 18 empleados, mientras las carpinterías sumaban otros 18 , igual que las panaderías.

\section{Los indígenas auxiliares}

Los datos de que disponemos sobre población indígena hacen referencia sólo a los residentes en la capital, Sidi Ifni, donde viven 5.662 nativos en $1968^{38}$; como esta ciudad concentra casi el $100 \%$ de los españoles residentes en la colonia, pensamos que la población indígena auxiliar también se reduciría a la censada en la capital.

La población nativa masculina de Sidi Ifni en 1968 ejercía las siguientes profesiones (tasa de actividad masculina 41\%):

\begin{tabular}{|lr|lr|}
\hline & Total & & Total \\
\hline Pescadores & 38 & Conductores & 51 \\
Panaderos & 12 & Servicios varios & 28 \\
Central Eléctrica & 6 & Militares & 214 \\
Jornaleros & 520 & Autoridades y notables del país & 16 \\
Comercio & 194 & Fokahas & 14 \\
& & Funcionarios & 53 \\
& & Docentes & 7 \\
\hline
\end{tabular}

Más de la cuarta parte de los activos indígenas son, pues, auxiliares o vinculados a la Administración española, sobre todo militares (de los que 134 eran policías); el mismo informe señala que en la ciudad había 521 nativos mutilados.

En Sidi Ifni también se censaba en $1968^{39}$ un grupo de 618 súbditos marroquíes, que llegaron entre 1934 y $1957^{40}$, unos con las tropas españolas que ocuparon Ifni en 1934, y otros en reclutamientos militares posteriores hechos en el antiguo Protectorado de España en Marruecos, o bien como funcionarios del Gobierno; de ellos, 151 ejercían actividades dependientes de la Administración española ${ }^{41}, 216$ eran jornaleros, 75 comerciantes, 33 hortelanos, 16 camareros, 19 albañiles, etc.

En suma, en 1968 la Administración española en Sidi Ifni empleaba a 976 españoles (militares y funcionarios civiles) y a 455 africanos, de los que 304 eran nativos de Ifni y 151 súbditos marroquíes; las últimas son cifras significativas ya que el total de población nativa masculina era estimado en 20.512 habitantes (en 1964), mientras los marroquíes sólo sumaban 618 en 1968; en este sentido, el Informe que comentamos señala que los súbditos marroquíes «...más cultos, eran preferidos a los nativos en los trabajos ofertados por la Administración» ${ }^{42}$. Por otra parte, la escasa integración de los nativos en la Administración española, también es manifiesta en la enseñanza que reciben: en 1968 había sólo 17 alumnos nativos en el Instituto de Sidi Ifni, y 194 en la Escuela Laboral.

38 AGA, Caja AF-S-239.

39 id.

40 A partir de 1957 se cortó esta inmigración de súbditos marroquíes a raíz del ataque realizado por el irregular Ejército de Liberación marroquí.

41 Entre ellos, 48 trabajan en el Gobierno de la provincia, 24 en el Ayuntamiento, 47 eran policías y 32 militares.

42 AGA, Caja AF-S-239. 
En correspondencia oficial de 1968 referida al cercano proceso de descolonización se teme que una vez sea integrado Ifni a Marruecos, actividades tan básicas como los servicios de agua, luz, puerto, frigoríficos, así como las huertas existentes, dejarían de funcionar por la falta de personal técnico, con lo que habría «ruina inmediata e inevitable»; se estimaba que sería necesario un período no inferior al año para formar adecuadamente a los nativos que se hicieran cargo de los servicios indicados ${ }^{43}$.

\section{Evacuación e indemnizaciones por descolonización}

Como en el caso del Sáhara, la descolonización de Ifni fue de tipo «evacuación», por lo que las autoridades preveían paralización de las actividades económicas, según se deduce de las afirmaciones que en este sentido menudean en la documentación oficial de la época: «...la evacuación - con motivo de la retrocesión a Marruecos - terminará con la prosperidad artificial de la zona, debida a la presencia de España», «...la evacuación española arrastrará la paralización del comercio, ...la ruina de los servicios..., la población actual de la provincia se reducirá al $25 \% \ldots{ }^{44}$, «en Ifni no existe otra riqueza que la aportación oficial de España...» ${ }^{45}$.

Según previsiones de las autoridades de la provincia de Ifni (enero de 1969), las indemnizaciones a conceder con motivo de la descolonización ascenderían a 161 millones de pesetas $^{46}$, repartidas en los siguientes conceptos: 1) 66'7 millones de pesetas para el transporte y daños de mobiliario; esta suma se destinaría a europeos, así como a los indígenas militares que optasen por establecerse en Ceuta, Melilla o Sáhara; 2) 46’4 millones por despido a asalariados residentes en Ifni, europeos o africanos 3) por cese o disminución de actividad: a comerciantes e industriales europeos 16,2 millones y a indígenas 10,6 millones; 4) 0,6 millones a agricultores y ganaderos europeos; 5) 5,8 millones a propietarios europeos por abandono de inmuebles; 6) 14,9 millones para imprevistos; 7) a personal indígena de las fuerzas armadas o «tropa mora»; 8) a funcionarios musulmanes. Para estos dos últimos capítulos no se fijan cantidades de indemnización por el momento. De las indemnizaciones indicadas, el reparto por tipo de beneficiario queda así: 1) funcionarios, 57,3 millones; 2) industriales, comerciantes, agricultores y ganaderos: a europeos 25 millones, a musulmanes 10,6 millones; 3) trabajadores por cuenta ajena: a europeos 37,6 millones, a musulmanes 15,5 millones.

El número de trabajadores nativos, empleados en empresas privadas y organismos de la Administración española, que reciben en junio de 1969 indemnizaciones por cese de actividad, ascienden a 296; en las mismas circunstancias se encontraban 150 trabajadores españoles, que abandonan el territorio de Ifni ${ }^{47}$.

Los titulares de comercios e industrias que piden indemnizaciones por cese de actividad son 185; de estos los grupos más numerosos son 29 taxistas, 15 propietarios de bares, 7 importadores-exportadores, 7 transportistas urbanos, etc., el resto incluye una amplia lista de 63 actividades diferentes; en general son pequeños comercios que proporcionan a sus dueños ingresos complementarios, pues 25 propietarios son simultáneamente trabajadores por cuenta ajena y 29 son funcionarios y esposas de funcionarios ${ }^{48}$; además, 64 propietarios

\footnotetext{
43 id.

44 id.

45 AGA, Caja AF-D-484.

46 id.

47 AGA, Caja AF-S-283.

48 id.

49 id.
} 
regentan al mismo tiempo varios tipos de negocios, con lo que los propietarios reales se reducen a 121. De estos, 110 indican las localidades españolas donde piensan establecerse al abandonar Sidi-Ifni: más de la mitad -66 propietarios- lo haría en las islas Canarias, y de ellos 60 en Las Palmas; el resto muestra preferencias muy dispersas, 6 en la provincia de Valencia, 6 en Málaga, 5 en Madrid, 4 en Sevilla, etc., en total, de los 44 que se dirigen a la península, 32 lo hacen a provincias costeras. Estas provincias elegidas como futuros lugares de residencia por los propietarios de Sidi Ifni, sin duda corresponden a los lugares de origen de estos españoles.

Otro dato que evidencia la escasa entidad económica de las actividades comerciales e industriales de Sidi Ifni es la cuantía de los préstamos solicitados para iniciar los nuevos negocios (generalmente comercios en la metrópoli): 50 solicitudes suman 63,7 millones de pesetas $^{49}$.

En marzo de 1969, el Gobierno local ofrece una relación de 92 familias españolas (que suman 404 personas) residentes en Sidi Ifni que desean trasladar su domicilio a la metrópoli; de ellas 23 se irían a Canarias, 9 a Valencia, 8 a Málaga, 7 a Almería, 7 a Melilla, 5 a Madrid, etc. Sus profesiones abarcan una amplia gama, pero casi siempre del sector terciario, e incluyen a médicos, docentes, administrativos, camareros, carpinteros, etc. ${ }^{50}$.

Ifni es la colonia española en África que muestra menor integración con la metrópoli, en lo que influyó su menor permanencia efectiva bajo administración española (19341969), la falta de actividades económicas del sector privado en este territorio, así como el bajo nivel de instrucción de los nativos, lo que incluso parece que originó su relativa postergación laboral frente a los súbditos marroquíes. Otro índice de falta de integración de Sidi Ifni podría ser el que su población nativa permanezca estacionada entre 1956 y 1967 (5.736 y 5.634 habitantes, respectivamente), mientras la europea crecía de 3.177 a 11.984 habitantes. Este cúmulo de hechos tal vez explique que el convenio hispano-marroquí de retrocesión de Ifni a Marruecos no considerase, tal como se hizo con la independencia de Marruecos o de Guinea, el traspaso de los funcionarios nativos a la Administración española. Por ello, el Consejo de Ministros de 10-XII-1969 acordó indemnizar a este personal como cancelación a sus derechos respecto a la Administración española, naturalmente con la oposición de los interesados que reclaman sus haberes o una pensión de retiro.

\section{III}

\section{La presencia española en Guinea Ecuatorial}

Entre las colonias españolas en África, Guinea Ecuatorial es la más antigua; la parte insular fue cedida por Portugal en 1777, mientras la Guinea continental administrada por España lo es desde finales del siglo XIX, con fronteras definitivas fijadas en 1900. Las dificultades sanitarias derivadas del clima repercuten, entre otras razones, en una presencia europea muy escasa hasta tiempos recientes: 523 habitantes de hecho censados en 1900, 1.539 en $1932,4.124$ en $19422^{51}, 3.937$ en $19500^{52}$, 7.086 en 1960 y 9.137 en 1967 . Región

50 AGA, Caja AF-S-165.

51 El Negociado de Estadística del Gobierno General de Guinea Ecuatorial inició su actividad en agosto de 1941. Las estadísticas del movimiento natural de la población se organizaron en 1942, aunque al principio los datos sólo son aceptables para la población europea. Vid. Dirección General de Marruecos y Colonias. Sección de Estadísticas de la Delegación del Trabajo del Gobierno General de los Territorios Españoles del Golfo de Guinea. Resúmenes de los años 1944 y 1945, 217 pp. Cf. pp. 8 y 66.

52 Esta disminución se debe a repatriación de personal militar. 
FIGURA 5. Evolución de la población europea de hecho en Guinea Ecuatorial (1950-1966).

autónoma desde 1964, Guinea Ecuatorial fue proclamada república independiente el 12-X1968.

Los fuertes incrementos de población europea posteriores a 1950 están vinculados al desarrollo económico de la colonia, que incrementa notablemente sus exportaciones agrícolas y madereras, las últimas en Guinea continental; los aumentos de población europea son equilibrados entre las dos provincias (Río Muni, continental, Fernando Poo, insular). Entre 1960 y 1967 la provincia de Fernando Poo acapara el 60-62\% del censo europeo, especialmente concentrado en su capital Santa Isabel, donde se localizan la mayor parte de los servicios coloniales; en esta ciudad viven la mitad de los europeos de toda la colonia y el $80 \%$ de los de su provincia; en Río Muni, la capital Bata concentra sólo la mitad de la población europea de la provincia.

La población censada en $1965^{53}$ muestra una paralización del incremento de europeos respecto a 1960 —incluso disminución en Río Muni-, reflejado en la natalidad; la explicación podría encontrarse en un cierto estancamiento en la producción económica de la colonia durante esos años ${ }^{54}$, además de las inquietudes que pudieran haber provocado las elecciones para instaurar el régimen autonómico en la colonia ${ }^{55}$. Si damos plena validez a la estadística de 1965, al año siguiente, 1966, se detecta un notable incremento de europeos en ambas provincias, aunque la tasa de natalidad se reduce mucho después del máximo de 1960: 32’4 por 1.000 en 1960, contra 20’6 en 1966.

\section{Las características geodemográficas}

La distribución por edades y sexos de los 3.937 europeos censados en 1950 - de los que 342 no son españoles, con los portugueses (203) como primera colonia extranjera-, nos muestra con claridad que es precisamente en esas fechas cuando se iniciaba en la colonia una tendencia decidida al establecimiento de familias. En efecto, a) la sex ratio aumenta de 368 en el año 1932 a 549 en 1942 (aumento de la presencia militar), mientras desciende a 224 en 1950 y a 165 en 1960; b) frente a una escasísima población entre 10 y 19 años de edad, el grupo de 0-4 años aumenta muy considerablemente; c) entre los europeos con más de 20 años de edad, el mayor equilibrio entre sexos se encuentra entre los de 25-34 años. No obstante, en 1950 aún persiste un abrumador predominio de varones entre los europeos censados en la colonia, especialmente entre los que tienen más de 35 años de edad; el contrastado escalonamiento de los grupos de edad, resalta la presencia laboral temporal de los varones, centrada entre los 25 y 40 años de edad.

53 Datos ofrecidos por la Delegación Regional de Estadística del Gobierno Autónomo de Guinea Ecuatorial, AGA, Caja AF-D-656.

54 Vid. estadísticas en La Región Ecuatorial Española hoy.

55 La votación se realizó el 15-XII-1963, AGA, Caja AF-D-486. 
Figura 6. Año 1950. Estructura por edad y sexo de la población europea en Guinea Ecuatorial.

Figura 7. Tasas de natalidad de la población europea en Guinea Ecuatorial (1950-1966).

El 89\% de la población europea censada en Guinea Ecuatorial en 1950 había nacido en la metrópoli, un $9 \%$ en la misma colonia, y el resto en el extranjero y en el Protectorado español de Marruecos. Casi dos tercios de los españoles procedían de provincias litorales, especialmente de Barcelona -337—y de las del litoral cantábrico - 604_; entre las del interior de la península sólo destacan los que proceden de Madrid -295—, sin duda funcionarios; como en las colonias de Sáhara e Ifni, Las Palmas es principal centro emisor de emigrantes - 213 - Las diferencias de sex ratio entre los emigrantes de cada provincia resultan llamativas: frente a una media de 252 varones por 100 mujeres, los procedentes de Madrid ofrecen el mayor equilibrio - 129-, sin duda relacionado con la mayor estabilidad laboral derivada de su status de funcionarios; en el extremo opuesto se sitúan los que proceden de las provincias más emigratorias, como las insulares - sex ratio de 316- y sobre todo los de Galicia, cuyos 397 emigrantes alcanzan una proporción de 786 varones por 100 mujeres. En total, el 43\% de la población europea censada en Guinea Ecuatorial en 1950 no tenía familia en la colonia.

\section{La situación económica y social en Guinea Ecuatorial}

La población activa originaria de la metrópoli que vivía en Guinea Ecuatorial ${ }^{56}$, aparte

56 Los nativos de Guinea Ecuatorial también son considerados españoles hasta la independencia de la colonia. Así, en el Censo de población del Golfo de Guinea de 1950, los habitantes indígenas de raza negra 
Cuadro VI

GUINEA ECUATORIAL. POBLACIÓN EUROPEA DE HECHO (1950-1966)

\begin{tabular}{|crrrr|}
\hline & $\mathbf{1 9 5 0}$ & $\mathbf{1 9 6 0}$ & $\mathbf{1 9 6 5}$ & $\mathbf{1 9 6 6}$ \\
\hline Total & 3.937 & 7.086 & 7.247 & 9.137 \\
Varones & 2.721 & 4.411 & & \\
Mujeres & 1.216 & 2.675 & & \\
Fernando Poo & 2.439 & 4.222 & 4.465 & 5.615 \\
Varones & 1.675 & 2.641 & & \\
Mujeres & 765 & 1.581 & & \\
Santa Isabel & 1.992 & 3.358 & & \\
Varones & 1.342 & 2.076 & & \\
Mujeres & 650 & 1.282 & & \\
Río Muni & 1.497 & 2.864 & 2.782 & \\
Varones & 1.047 & 1.770 & & \\
Mujeres & 450 & 1.094 & & \\
Bata & 698 & 1.534 & & \\
Varones & 487 & 967 & & \\
Mujeres & 211 & 567 & & \\
\hline
\end{tabular}

Fuente: Para 1950 y 1960, INE, Anuario Estadístico de España. Para 1966 y 1967, AGA, Caja AF-D-656.

Cuadro VII

GUINEA ECUATORIAL. MOVIMIENTO NATURAL DE LA POBLACIÓN EUROPEA

\begin{tabular}{|cccc|}
\hline Año & Nacimientos & Defunciones & Matrimonios \\
\hline 1950 & 84 & 18 & 8 \\
1951 & 116 & 20 & 10 \\
1952 & 135 & 18 & 4 \\
1953 & 129 & 11 & 7 \\
1954 & 138 & 16 & 11 \\
1955 & 171 & 16 & 15 \\
1956 & 168 & 17 & 10 \\
1957 & 201 & 27 & 19 \\
1958 & 203 & 16 & 20 \\
1959 & 219 & 28 & 23 \\
1960 & 215 & 19 & 12 \\
1961 & 254 & 23 & 39 \\
1962 & 181 & 20 & 17 \\
1963 & 192 & 33 & 9 \\
1964 & 223 & 15 & 20 \\
1965 & 190 & 19 & 15 \\
1966 & 211 & 25 & 21 \\
1967 & 164 & 18 & \\
\hline
\end{tabular}

Fuente: INE, Anuario Estadístico de España; Dirección General de Plazas y Provincias Africanas, Resumen Estadístico del África Española; AGA, Caja AF-D-656. 
los funcionarios y propietarios, generalmente ejercía actividades de dirección o que requerían cierta especialización profesional. Así, un informe de las autoridades de la colonia de febrero de 1961, indica que los trabajadores blancos en Guinea «... dirigen y su categoría mínima es la de encargado», al mismo tiempo que desaconseja que acudan a la colonia como simples braceros, pues como tales «..no soportarían el clima, enfermarían. Con ellos la producción tendría precios elevadísimos, y socialmente se establecerían dos clases de trabajadores blancos...» ${ }^{57}$.

Una relación de 1.546 españoles repatriados de Guinea en $1969{ }^{58}$ indica el siguiente cuadro profesional:

1) Propietarios de explotaciones madereras-3

2) Empleados y encargados de explotaciones madereras y plantaciones de aceite de palma-80

3) Propietarios agricultores- 98

4) Empleados y encargados de explotaciones agrícolas-320

5) Propietarios de comercios y factorías- 244

6) Empresarios de la construcción-12

7) Empleados y encargados de la construcción-60

8) Propietarios de talleres mecánicos y reparaciones- 18

9) Empleados y mecánicos-112

10) Empleados portuarios-28

11) Funcionarios-239

12) Profesiones liberales-43

13) Encargados de empresas e intermediarios- 89

14) Varios (profesionales medios, trabajadores de compañías pesqueras, oficios diversos)-98

La distribución por edades de este contingente de trabajadores era el que sigue: $21 \%$ menores de 25 años, $39 \%$ entre 26 y 40 años, $24 \%$ entre 41 y 50 años, y $4 \%$ mayores de 60 años.

A partir del Padrón de habitantes de 1965, el Servicio de Estadísticas de Guinea elaboró una clasificación de la población activa referida a la total de la colonia (vid. cuadro VIII). Destaca el abrumador predominio en el sector agrario, tanto en las generalizadas pequeñas explotaciones de los nativos, como en las explotaciones mayores, cuyos cultivos principales son el cacao (en Fernando Poo) y el café (especialmente en Río Muni), seguidos de bananas (Fernando Poo); en Río Muni destaca la explotación maderera realizada principalmente por 19 grandes sociedades, forma de explotación que también incluye a la palmera de aceite ${ }^{59}$.

Aunque los datos de población activa de 1965 se ofrecen de forma conjunta para nativos y europeos, se observa la influencia del terciario en la capital de Fernando Poo (administrativos, vendedores, fuerzas armadas).

siempre son designados como «españoles»; por otra parte, en documentos de la Administración española posteriores a la independencia, también se hace referencia a la nacionalidad española de los guineados hasta la independencia de la colonia (AGA, Caja AF-D-481).

57 AGA, Caja AF-D-783.

58 AGA, Caja AF-D-480.

59 La Región Ecuatorial al día, Madrid, 1963. 


\section{Cuadro VIII}

GUINEA ECUATORIAL. DISTRIBUCIÓN DE LA POBLACIÓN ACTIVA. AÑO 1965

\begin{tabular}{|c|c|c|c|c|c|c|}
\hline \multirow[t]{2}{*}{ Profesiones } & \multicolumn{2}{|c|}{ Fernando Poo } & \multicolumn{2}{|c|}{ Río Muni } & \multicolumn{2}{|c|}{ Total } \\
\hline & número & $\%$ & número & $\%$ & número & $\%$ \\
\hline Agricultores, gana- & & & & & & \\
\hline deros y pescadores & 22.175 & $71 ’ 2$ & 47.243 & 73’1 & 69.418 & $72^{\prime} 5$ \\
\hline Artesanos y similares & 2.495 & $8^{\prime} 0$ & 4.045 & $6 ’ 3$ & 6.540 & 698 \\
\hline Profesionales, técnicos & & & & & & \\
\hline $\mathrm{y}$ asimilados & 506 & $1 ' 6$ & 1.467 & $2 ’ 3$ & 1.973 & 2'1 \\
\hline $\begin{array}{l}\text { Administrativos, gerentes } \\
\text { y directores }\end{array}$ & & $0{ }^{\prime} 4$ & & 't & & $0^{\prime} 4$ \\
\hline $\begin{array}{l}\text { y directores } \\
\text { Empleados oficina }\end{array}$ & $\begin{array}{l}143 \\
987\end{array}$ & 3,2 & $\begin{array}{r}250 \\
1.433\end{array}$ & 2,2 & $\begin{array}{r}393 \\
2.420\end{array}$ & $\begin{array}{l}04 \\
2,5\end{array}$ \\
\hline Fuerzas armadas & 1.181 & $3 ' 8$ & 1.758 & 277 & 2.939 & 3,1 \\
\hline Transporte y & & & & & & \\
\hline comunicaciones & 799 & $2^{\prime} 6$ & 2.087 & $3 ’ 2$ & 2.886 & $3^{\prime} 0$ \\
\hline Vendedores & 1.252 & $4^{\prime} 0$ & 1.882 & $2 ’ 9$ & 3.134 & $3 ’ 3$ \\
\hline Servicios, deporte y & & & & & & \\
\hline diversiones & 1.066 & $3 ’ 4$ & 2.504 & $3 ’ 9$ & 3.570 & 3'7 \\
\hline No clasificados & 556 & $1^{\prime} 8$ & 1.930 & 3’0 & 2.486 & $2^{\prime} 6$ \\
\hline Total activos & 31.160 & $100^{\prime} 0$ & 64.599 & $100 ’ 0$ & 95.759 & $100 ’ 0$ \\
\hline Tasa de actividad & & $48 ’ 9$ & & $33^{\prime} 8$ & & $37^{\prime} 6$ \\
\hline
\end{tabular}

Fuente: AGA, Caja AF-D-656.

La acusada diferencia de tasa de actividad entre ambas provincias - 48'9\% en Fernando Poo, 33'8\% en Río Muni- se debe a la elevada inmigración de trabajadores masculinos que llegan a Fernando Poo procedentes de Nigeria, ya que los naturales de la isla no cubrían las necesidades laborales de su agricultura. Es una inmigración relativamente antigua, pues el censo de 1942 ya señala en Fernando Poo 19.031 extranjeros africanos, con una sex ratio de 903 varones por 100 mujeres; en Guinea continental estos extranjeros de raza negra eran menos, 5.325, con sex ratio de 223 , dedicados principalmente a explotaciones forestales. Los inmigrantes de raza negra en Fernando Poo procedían en un $79 \%$ de Nigeria, un 19\% del Camerún y el $2 \%$ restante de Liberia y Santo Tomé ${ }^{60}$.

En 1950 los extranjeros de raza negra han aumentado notablemente: 12.263 en Guinea continental — sex ratio de 138 - y 23.306 en Fernando Poo — sex ratio de 457-; mientras en Guinea continental el $81 \%$ de los inmigrantes de raza negra procedían de Gabón y Camerún francés, en Fernando Poo el $86 \%$ procedían de Nigeria ${ }^{61}$. Si en los datos censales de 1960 asimilamos transeúntes de raza negra con extranjeros, esta inmi-

60 Territorios españoles del Golfo de Guinea. Resúmenes de los años 1946 y 1947, pp. 30-31.

61 Censo de los territorios españoles del Golfo de Guinea, de 1950, pp. 155-157. 
gración parece estabilizada respecto a 1950, pues en Fernando Poo se censan como transeúntes 23.490 - sex ratio de 425- y 9.273 en Río Muni — sex ratio de 357-.

Tan importante afluencia de trabajadores nigerianos a Fernando Poo, cada vez más acompañados de sus esposas, llegó a preocupar a las autoridades coloniales ante una posible reivindicación de la isla por parte de Nigeria; por esta razón se intentó —año 1961 - solucionar el problema con la inmigración de trabajadores nativos de Alto Volta, e incluso con españoles de la metrópoli, en ambos casos con respuesta negativa: por oponerse las autoridades de Alto Volta, y por juzgarlo contraproducente - social y economicamente- en el caso de españoles de la metrópoli ${ }^{62}$. Los temores sobre la soberanía futura de la isla se basaban en que en 1950 los habitantes de raza negra nativos de Fernando Poo eran 14.735, frente a 20.031 nigerianos censados allí, todo ello «apoyado» por la situación de la isla frente a las costas de Nigeria.

Así pues, según lo indicado parece había una notable segregación entre la población blanca y la de color en el ejercicio de actividades económicas en el sector privado. La separación parece menor entre los activos del sector público, a resultas de los centros formativos establecidos por la Administración colonial. Así, en la capital Santa Isabel había una Escuela Superior Provincial donde se formaba, en régimen de becarios internos, a los futuros funcionarios - docentes y de la Administración- de la colonia; también existía una Escuela de Capacitación Sanitaria para la formación de sanitarios con destino a los hospitales; en 1960-61 había 164 universitarios guineanos becados en las universidades de la metrópoli ${ }^{63}$.

En efecto, una estadística del «Escalafón de funcionarios del Cuerpo General auxiliar de la Administración civil del Gobierno autónomo de la Guinea Ecuatorial» de enero de 1967, suma 3.841 funcionarios, de los que 691 proceden de la metrópoli y 3.150 son nativos $^{64}$; entre los últimos destacan 370 en la enseñanza primaria, 658 en el servicio sanitario, 100 en la Delegación de Hacienda, 68 en el Servicio Agronómico, 98 en Correos, 236 en la policía gubernativa, 114 en la guardia marítima y 896 en la guardia territorial.

\section{Una repatriación inesperada}

La independencia de Guinea Ecuatorial fue proclamada el 12-X-1968. Las relaciones entre la antigua metrópoli y el nuevo Estado fueron, en un principio, de estrecha colaboración; en efecto, para «evitar que el acceso a la independencia pueda provocar dificultades de continuidad de los servicios públicos $»^{65}$, permanecieron en la ex-colonia numerosos funcionarios españoles, tanto civiles como militares, así como la mayoría del personal civil español ${ }^{66}$ : los primeros por convenio entre ambos gobiernos, y los segundos por la posibilidad de continuar sus actividades económicas.

Sin embargo, la inestabilidad política interna desembocó en intento de golpe de estado y, como consecuencia, produjo la evacuación precipitada — en marzo de 1969- de todos los españoles residentes en la ex-colonia, operación culminada a principios de abril de

62 AGA, Caja AF-D-783.

63 La Región Ecuatorial Española al día, pp. 17-20.

64 AGA, Caja AF-D-560.

En 1961 un informe de la Delegación de Estadística en Santa Isabel señala para la colonia 727 funcionarios «de todas clases» originarios de la metrópoli, y 2.904 nativos de Guinea (AGA, Caja AF-G-1.949).

65 AGA, Caja AF-D-481.

66 AGA, Caja AF-D-480 y AF-D-481. 
1969 con la repatriación de las fuerzas de la Guardia Civil. Estos acontecimientos provocaron que los españoles repatriados de Guinea tuvieran que abandonar allí sus bienes.

Dada la aparente cordialidad con la que se hizo la transferencia de soberanía en Guinea Ecuatorial, el Gobierno de España no previno indemnizaciones de carácter general para la repatriación de los españoles ${ }^{67}$. Sin embargo, la forma precipitada en que esta se produjo en marzo de 1969, obligó a crear, el 25 de marzo de 1969, una Comisión Interministerial para atender a los trabajadores llegados desde Guinea ${ }^{68}$.

En efecto, la mayor parte de los repatriados llegaron a Madrid por vía aérea, con lo que la petición de ayuda a las autoridades se produjo de inmediato y directamente: «A la Dirección General de Plazas y Provincias Africanas están llegando todos los días repatriados de Guinea, entre los que se encuentran numerosos empleados y trabajadores particulares y pequeños propietarios agrícolas o de negocios, que han dejado allí todos sus medios de vida, mobiliario y hasta ropas, puesto que muchos de ellos han llegado con la imprescindible ropa tropical» (nota de 22-III-1969) ${ }^{69}$. Las necesidades de los repatriados a resultas de la inesperada y acelerada evacuación eran tales que, en el aeropuerto de Barajas (Madrid) hubo que instalar un servicio asistencial desde el 3 de marzo de 1969, que proporcionaba alojamiento, comida, ropa y billetes de tren en caso de que los repatriados lo necesitasen.

En la primera reunión de la Comisión Interministerial para ayudar a los repatriados de Guinea, efectuada el 28-III-1969, se informa que hasta esa fecha el número de españoles repatriados es de 3.425 por vía aérea y 471 por vía marítima, mientras estiman que los españoles en Guinea serían unos 6.500, entre los que había unos 1.700 asalariados en las empresas españolas con actividades en la ex-colonia. Se esperaba una evacuación total, excepto «30 ó 40 que quedarían en África por estas casados con guineanas y otros motivos». La Comisión enumera como campo prioritario de su actuación: a) encontrar empleo para los trabajadores por cuenta ajena; b) la readaptación de los pequeños comerciantes, industriales y propietarios agrícolas; c) ayudas para obtener viviendas; y d) indemnizaciones que cubran los gastos de repatriación; quedaban excluidos de la acción de la Comisión las grandes empresas, así como los funcionarios y contratados de la Administración, pues éstos, como ocurre con la independencia del resto de colonias españolas en África, son integrados en las correspondientes administraciones de la metrópoli.

Para solucinar los problemas enumerados, en diversas fechas de 1969 la Administración tramita créditos diversos: a) 10 millones de pesetas para ayudas inmediatas a los repatriados, que reciben 2 entregas de 7.000 pesetas cada una por cabeza de familia ${ }^{70}$; b) 60 millones de pesetas para la Agrupación de empresarios de Guinea al objeto de que puedan satisfacer los salarios de sus trabajadores de raza negra; c) 34 millones de pesetas para bienestar infantil e integración social de los repatriados; d) se otorgó un seguro de desempleo de hasta 3 años a los trabajadores españoles por cuenta ajena; además, los asalariados mayores de 40 años podían prorrogar durante 2 años más el seguro de desempleo - 6.000 pesetas/mes_-; e) Bancos paraestatales abrieron una línea de crédito de 600 millones de pesetas para los empresarios, que podían recibir hasta 250.000 pesetas con

67 AGA, Caja AF-D-480.

68 En esta Comisión estaban representados los Ministerios de Trabajo, de Asuntos Exteriores y de Hacienda, y las Direcciones Generales de Política Interior, de Asistencia Social y la de Plazas y Provincias Africanas.

69 AGA, Caja AF-D-480.

70 Los funcionarios de Guinea recibieron 25.000 pesetas para el titular y 5.000 por esposa y por cada hijo. 
sólo garantía personal — fórmula a la que se acogieron muchos—y hasta 1,5 millones con garantía legal.

El 24-IV-1969, según la Comisión Interministerial, los españoles repatriados sumaban 5.009 , de los que 3.809 por vía aérea y 1.200 por vía marítima; en 1978 se estimaba en 6.000 los españoles repatriados ${ }^{71}$. Su distribución por provincias — deducida a partir de 1.175 ayudas concedidas - coincide con los lugares de origen de la población española en Guinea que ofrecía el Censo de 1950, es decir destaca Madrid, seguida de Barcelona, así como las provincias del litoral cantábrico y de Galicia.

Las indemnizaciones ofrecidas por el Gobierno español a los repatriados de Guinea fueron juzgadas insuficientes, especialmente por los empresarios; así, son pedidas indemnizaciones por abandono de bienes en Guinea, por pérdida de contratos, etc. Para aunar reivindicaciones de indemnizaciones se crearon dos asociaciones con sede en Madrid: «Asociación de antiguos residentes españoles en Guinea Ecuatorial» y «Comunidad de españoles con intereses en África»; la primera agrupaba a empleados y comerciantes modestos $^{72}$, mientras en la segunda se encontraban las empresas más importantes (madereras, agrícolas y comerciales), aunque no exclusivamente. La segunda asociación, constituida el 22-IV-1971, en 1978 tenía 294 miembros, que continuaban reivindicando indemnizaciones, sin duda elevadas ${ }^{73}$; así, en 1970, ocho empresas forestales con explotaciones en Guinea Ecuatorial valoraban la cesión de sus patrimonios en 936 millones de pesetas, de los que 727 correspondían a las explotaciones forestales y 209 a las plantaciones agrícolas (cacao, café, palmiste) ${ }^{74}$. En 1973, los españoles propietarios en Guinea valoraban sus pérdidas en 4.500 millones de pesetas ${ }^{75}$. En 1978 se pensaba en constituir una Comisión de trabajo interministerial para estudiar las indemnizaciones solicitadas por la «Comunidad de españoles con intereses en África», pues la primera Comisión Interministerial creada en 25-III-1969, fue disuelta en julio de $1970^{76}$. Los repatriados solicitantes de indemnizaciones apoyan sus argumentos en las ayudas similares concedidas por el Gobierno español con ocasión de la independencia de Marruecos (1956), de Ifni (1969) y de Sáhara (1975).

El deterioro de las relaciones entre la República de Guinea Ecuatorial y España iniciado en 1969, llevó a que la primera, en 1973, desposeyera de su nacionalidad guineana a los estudiantes de aquel país en España que no habían querido regresar a Guinea en el plazo fijado ${ }^{77}$; durante el curso académico 1974-75 había en España 41 estudiantes universitarios guineanos, mientras en 1973 se estimaba que los ciudadanos de Guinea Ecuatorial residentes en España eran entre 1.000 y 1.500 , de los que 124 eran estudiantes becados ${ }^{78}$; después de 1979 (año de cambios políticos en Guinea Ecuatorial) la emigración de guineanos a España ha aumentado mucho.

71 AGA, Caja AF-D-480.

72 En 1976 continuaba solicitando al Gobierno ayudas para los repatriados, AGA, Caja AF-D-480.

73 AGA, Caja AF-D-480.

74 AGA, Caja AF-D-465.

75 AGA, Caja AF-D-481.

76 AGA, Caja AF-D-465.

77 Según las Resoluciones Generales del Tercer Congreso Nacional del Partido Único Nacional de Trabajadores, fechadas en Bata el 13 de julio de 1973 (página 5), AGA, Caja AF-D-481.

78 AGA, Caja AF-D-481. 


\section{Los españoles en el Protectorado de Marruecos}

El Protectorado español situado en el norte de Marruecos, fija sus fronteras en $1912^{79}$ sobre una superficie de poco más de $20.000 \mathrm{~km}^{2}$, y proclama su independencia en 1956; en 1955 vivía aquí una población total estimada de 1.054.978 habitantes, de los que 90.939 eran españoles. A estos habría que añadir los españoles censados en el Marruecos bajo protectorado francés que en 1951 eran $25.698^{80}$, así como los residentes españoles en Tánger, que son 15.486 en $1941^{81}$ y más de 21.500 a mitad de los años $1950{ }^{82}$.

Entre 1935 y 1955 la población española en el Protectorado se multiplica por 2 (Vid. Cuadro IX), con lo que su proporción sobre el censo total pasa del $5,6 \%$ al $8,6 \%{ }^{83}$; el incremento mayor en la población española es el registrado en 1935-40 (guerra civil española), con un $7,1 \%{ }^{84}$ anual medio, y el menor, lógicamente, se registra en el intercensal que precede a la independencia, con un $1,4 \%$ anual.

\section{Concentración urbana de los españoles}

La población española censada en el Protectorado de Marruecos es fundamentalmente urbana: las ciudades de Tetuán, Larache, Alcazarquivir, Villa Sanjurjo y Villa Nador concentran en el período 1935-1955 en torno a las tres cuartas partes de todos los españoles. Si a las citadas ciudades añadimos el resto de pequeños núcleos que las estadísticas oficiales también consideran como urbanos, el porcentaje de población urbana española se sitúa entre el 87 y $94 \%$ del total.

La población española de Tetuán, capital del Protectorado, destaca sobre la del resto de ciudades tanto por su censo total como por su mayor incremento: en 1935 la ciudad albergaba a 12.750 españoles, que casi se doblan cinco años después, al terminar la guerra civil española, y llegan hasta 29.000 en 1945; en los diez años que siguen crece con más lentitud. Larache, segunda ciudad en número de españoles, tenía 9.585 en 1935 y 13.509 en 1955. En las ciudades marroquíes tradicionales los españoles apenas si llegan a sobrepasar

79 Mediante el Tratado hispano-francés de 27-XI-1912, AGA, Caja AF-D-484.

80 Royaume du Maroc. Ministère de l'Economie nationale, Annuaire statistique du Maroc (ex-zone Sud), 1955-1956, p. 31.

81 Ministerio de Trabajo, Dirección General de Estadística, Zona de Protectorado y de los territorios de soberanía de España en el norte de África. Anuario Estadístico. 1944, Madrid, 1945, p. 23.

82 Vid. nota (1).

83 El primer «censo» de población realizado en el Protectorado español de Marruecos data de 1930, pues la pacificación-ocupación no termina hasta 1927. Sin embargo, en junio de 1942, una Memoria redactada en Tetuán por el Jefe de los Servicios de Estadística de la zona de Protectorado, afirma «con la denominación de Censo de Población se han realizado en la Zona, en la parte Rural por los Servicios de Intervención y en las Ciudades por las Juntas de Servicios Municipales, unos recuentos numéricos, sin que por las informaciones recogidas se desprenda que para su formación se hayan tomado las mínimas garantías y por tanto es peligroso hacer entre ellos ningún cálculo comparativo...» (AGA, Caja AF-M-2.100).

El Censo de población de 1950 — de facto realizado en octubre de 1951— es, en opinión de Daniel Noin, mucho más aceptable, aunque contenga una probable subestimación de la población marroquí (Noin, D., $L a$ population rurale du Maroc, 1970, t. I, p. 33.

84 Esta tasa de crecimiento está referida a la población civil, con sex ratio de 102 en 1940. A principios de 1936 las tropas españolas en Marruecos ascendían a más de 34.000 hombres, según Morales Lezcano, V., España y el norte de África: el Protectorado en Marruecos (1912-1956), 1986, 2a ed., p. 182. 
Figura 8. Evolución de la población española de hecho en el Protectorado español de Marruecos (1935-1955).

Figura 9. Censo de 1950: distribución de la población en los núcleos urbanos, según Dirección General de Estadística, Zona de Protectorado y de los territorios de soberanía de España en el Norte de África, Anuario Estadístico de 1951. 


\section{Cuadro IX}

PROTECTORADO ESPAÑOL EN MARRUECOS. POBLACIÓN ESPAÑOLA DE HECHO (1935-1955)

\begin{tabular}{|crrrrr|}
\hline & $\mathbf{1 9 3 5}$ & $\mathbf{1 9 4 0}$ & $\mathbf{1 9 4 5}$ & $\mathbf{1 9 5 0}$ & $\mathbf{1 9 5 5}$ \\
\hline Total & \multirow{2}{*}{44.379} & 62.438 & 72.096 & 84.716 & 90.939 \\
Varones & & 31.475 & 34.974 & 50.518 & 53.542 \\
Mujeres & & 30.963 & 37.122 & 34.198 & 37.397 \\
& & & & & \\
Población urbana & 41.660 & & 63.085 & 75.901 & 82.125 \\
Varones & & & 30.336 & 44.336 & 47.360 \\
Mujeres & \multirow{2}{*}{2.719} & & 32.749 & 31.565 & 34.765 \\
Población rural & & 9.011 & 8.815 & 8.814 \\
Varones & & & 4.638 & 6.162 & 6.182 \\
Mujeres & & & 4.373 & 2.633 & 2.632 \\
\hline
\end{tabular}

Fuente: Ministerio de Trabajo. Dirección General de Estadística, Zona de Protectorado y de los territorios de soberanía de España en el norte de África. Anuario Estadístico. Estos datos no incluyen la población residente en Tánger y su zona.

un tercio de su censo total ${ }^{85}$, como en Tetúan en 1950 y 1955; en Larache la proporción se mantiene entre 30 y $31 \%$, y ya es mucho más baja en Alcazarquivir, Arcila y Xauén, donde los españoles representan entre el 9 y $18 \%$ del total de habitantes. El resto de ciudades y pequeños núcleos conceptuados como «urbanos» en las estadísticas del Protectorado - 18 núcleos en 1935, 12 en 1955- son «o bien de fundación reciente o transformaciones de insignificantes poblados indígenas ${ }^{86}$, lo que se traduce en predominio de la población española: en 1935 los españoles eran el 93\% en Villa Sanjurjo, 60\% en Villa Nador o 100\% en Castillejos, aunque en 1955 esta proporción se ha rebajado, a veces considerablemente (Vid. Cuadro X) ${ }^{87}$.

\section{Características geodemográficas}

La sex ratio de los españoles censados en el Protectorado está relativamente equilibrada en 1940-45, mientras se incrementaba notablemente en 1950 y 1955, con 148 y 143

85 Los Anuarios Estadísticos del Protectorado español son críticos sobre las cifras totales de población que ofrecen. Así, el del año 1947 (página 19), comenta, «El Servicio de Estadística continúa manteniendo sus reservas sobre la fiabilidad de estas cifras [totales de población entre 1930 y 1945], posiblemente influenciadas por los censos de racionamiento tan difíciles de llevar a cabo en el medio indígena».

86 Ministerio de Trabajo. Dirección General de Estadística, Zona de Protectorado y de los territorios de soberanía de España en el norte de África. Anuario Estadístico, 1941, p. 22.

87 Entre los núcleos «urbanos» nacidos con motivo de la ocupación española del Protectorado, la mayoría surgieron al amparo de los campamentos militares españoles: así, Villa Nador en 1908, aunque hasta 1915 no creó su primera Junta de Arbitrio; Rincón El Medik, a 16 km de Tetuán, surge junto al campamento militar establecido allí en 1913 con motivo de la ocupación de Tetuán; e igual sucede con Tarquist (1926), Puerto Capaz (1926), Karia de Arquemán, Monte Arruit, Segangan, Zaio y Zeluán. Villa Sanjurjo conmemora el desembarco de Alhucemas (año 1925), fundada con el nombre de Villa Alhucemas. Castillejos, a $8 \mathrm{~km}$ de Ceuta, nace en 1911 como apoyo a la construcción de una fábrica de cerámicas que empezó a funcionar en 1914 (vid. Delegación de Asuntos Indígenas. Servicio de Intervenciones, Anuario, Tetuán, junio 1955, 505 pp. mecanografiadas, en Biblioteca Nacional, Madrid). 
Figura 10. Año 1951. Estructura por edad y sexo de la población española en el Protectorado francés de Marruecos.

Figura 11. Tasas de natalidad y mortalidad de la población española en el Protectorado español de Marruecos (1940-1955).

varones por 100 mujeres, respectivamente. Este desequilibrio entre sexos se produce por varias causas: a) disminución del número de mujeres, fundamentalmente en medio rural donde la sex ratio pasa de 106 en 1945 a 235 en 1950 y 1955; b) fuerte aumento de la cifra absoluta de varones, pues si en 1945 se contabilizaban 34.974 varones y 37.122 mujeres, en 1950 son 50.518 y 34.198, respectivamente. Los cambios indicados pueden ser interpretados: 1) como «preparación» a la evacuación, especialmente en la disminución del número de mujeres españolas, mucho más acentuada en medio rural; en el perfil de la pirámide de edades de los españoles censados en 1951 en el Protectorado francés de Marruecos, se observa una anómala muesca femenina entre 25 y 40 años de edad, que también pudiera responder a su salida del país ante una previsible inestabilidad por la cercanía de la independencia. 2) El gran incremento de varones en el Protectorado español en 1950 también puede ser debido a la inmigración laboral atraída por los planes quinquenales de desarrollo del Protectorado iniciados en 1946; en efecto, si el primero estuvo dedicado fundamentalmente a las obras públicas, el de 1951 fue más diversificado en sus actuaciones ${ }^{88}$. Las cifras del movimiento de pasajeros españoles con Marruecos pueden apoyar la última interpretación, pues entre 1945 y 1954 se acumulan elevados saldos de emigrantes españoles, que destacan sobre los registrados en el período 1882-1956 (Vid. Cuadro XI).

Los españoles censados en el Marruecos francés en 1951 muestran acusados desequilibrios entre sexos, en los grupos de adultos predominan los varones mientras en los viejos las mujeres son mayoritarias. El desequilibrio a favor de los varones se explica por tratarse de una inmigración laboral, que retorna a su lugar de origen entre los 55 y 65 años de edad, como indican los pronunciados entrantes del perfil masculino de la pirámide. La perma-

88 García Figueras, Tomás, España y su Protectorado en Marruecos, 1912-1956, Madrid, 1957, p. 19. 
nencia de las mujeres con más de 60 años de edad —el escalonamiento de su perfil es regular-, se explica, sin duda, por motivos matrimoniales, pues la mayoría de las que se casan allí lo hacen con no españoles: así, en 1950 y $1951{ }^{89}$ contrajeron matrimonio 497 españolas y 305 españoles; de éstos además, sólo 121 casaron con española, mientras 149 lo hacían con francesas.

Las tasas de natalidad de la población española en el Protectorado son superponibles a las cifras medias de España, es decir en torno a 23 por 1.000 al principio de los años 1940, y a 20 por 1.000 en los años 1950; no obstante, estas cifras pueden experimentar desviaciones: así en 1940, en Tetuán — capital del Protectorado — la tasa es de 26,7 por 1.000, en Villa Sanjurjo 25,7, pero en Villa Nador sólo alcanza el 15,6, diferencias que traducen distintas situaciones de la sex ratio.

Sobre el lugar de nacimiento de los españoles residentes en Marruecos apenas disponemos de información ${ }^{90}$, aunque, como en otros casos ya analizados, son las áreas de la metrópoli más cercanas las que parece tienen considerable influencia. Así, en 1942 la máxima autoridad estadística en el Protectorado informa que los españoles residentes allí proceden principalmente de «la baja Andalucía», aunque en la parte oriental del Protectorado son abundantes los «levantinos» (originarios de las provincias de Alicante, Murcia, Almería) que amplían hasta esa región sus tradicionales lugares de emigración constituidos «por el Oranesado y Argelia». Una parte considerable de la inmigración española obrera estaba formada, en 1942, por antiguos soldados que al terminar sus obligaciones militares se domiciliaban en el Protectorado, y una vez establecidos atraían a familiares de la península ${ }^{91}$.

\section{La situación económica y social}

La colonia española en el Protectorado es fundamentalmente de residencia «urbana» - en torno al 90\%- (vid. cuadro X). Las explicaciones de tal hecho las sintetiza bien en 1942 el Jefe de los Servicios de Estadística del Protectorado, «La población obrera europea... suele ser obrera industrial poco especializada, pues aunque muchos proceden de la clase campesina, el elevado precio de las tierras, debido a las pocas disponibles, la inseguridad en el campo y el cultivo minifundista, les impelía forzosamente a localizarse en las ciudades» ${ }^{92}$; por otra parte, las diferencias salariales entre obreros industriales y agrícolas podían ser importantes a favor de los primeros ${ }^{93}$.

Las difíciles condiciones naturales para las actividades agrarias en el norte de Marruecos son bien conocidas, con la excepción de la fachada atlántica. Los datos recogidos sobre la propiedad agraria en manos de españoles, corroboran las afirmaciones citadas del Jefe de Estadística. Así, en $1943{ }^{94}$ los colonos establecidos en el Protectorado español eran 304, cuya situación es calificada de «poco favorable» en la documentación oficial; sus explotaciones suman 23.180 hectáreas de secano (bastantes sin cultivar), 590 de regadío y 1.131 calificadas de «regadío y secano»; del total, 21.962 ha eran en propiedad y 2.940 arrendadas. Dado el fortísimo predominio del secano, la estructura de las explotaciones es muy

89 Gouvernement Cherifien. Service central des Statistiques, Annuaire Statistique de la zone française du Maroc. 1950-1951, Rabat, pp. 68-71.

90 Sólo hemos tenido acceso parcial a la documentación solicitada al Archivo General de la Administración, pues la mayor parte no pudo ser consultada al encontrarse en proceso de revisión.

91 AGA, Caja AF-M-2.100. Asimismo, en 1949 correspondencia fechada en Granada corrobora la abundancia de emigrantes desde esta provincia hacia Marruecos (AGA, Caja AF-M-2.480).

92 AGA, Caja AF-M-2.100.

93 Bonmatí Antón, J.F., ob. cit. p. 232. AGA, Caja AF-M-2.100.

94 AGA, Caja AF-M-2.354 (ante. Leg. 4.007). 
Cuadro X

PROTECTORADO ESPAÑOL EN MARRUECOS. POBLACIÓN ESPAÑOLA EN

«NÚCLEOS URBANOS»

\begin{tabular}{|c|c|c|c|c|c|c|c|c|c|c|}
\hline & 1935 & & 1940 & & 1945 & & 1950 & & 1955 & \\
\hline Núcleos & españoles & $\%$ & españoles & $\%$ & españoles & $\%$ & españoles & $\%$ & españoles & $\%$ \\
\hline Tetuán & 12.750 & 25,7 & 22.103 & 31,5 & 29.004 & & 29.232 & 36,2 & 32.159 & 38,0 \\
\hline Larache & 9.585 & 32,5 & 11.568 & 32,0 & 10.847 & & 12.409 & 29,6 & 13.509 & 31,7 \\
\hline Alzacarquivir & 3,080 & 10,0 & 3.559 & 10,7 & 3.100 & & 3.350 & 10,5 & 3.759 & 11,6 \\
\hline Arcila & 1.451 & 23,6 & 1.335 & 12,4 & 1.457 & & 2.495 & 18,1 & 2.553 & 18,5 \\
\hline Xauén & 536 & 8,8 & 1.700 & 13,7 & 1.099 & & 2.446 & 18,0 & 2.603 & 18,1 \\
\hline Villa Nador & 2.810 & 59,8 & 5.978 & 67,7 & 6.050 & & 8.506 & 38,5 & 9.165 & 39,1 \\
\hline Villa Sanjurjo & 4.458 & 93,3 & 5.416 & 76,7 & 5.517 & & 7.148 & 66,6 & 7.730 & 67,9 \\
\hline Río Martín & 1.476 & 72,5 & 1.390 & 45,8 & 1.480 & & 1.807 & 47,6 & 1.834 & 46,6 \\
\hline Targuist & 924 & 77,8 & 892 & 69,5 & 663 & & 1.035 & 64,1 & 1.076 & 34,5 \\
\hline Beni-Ensar & 870 & 98,3 & & & & & & & & \\
\hline Segangan & 837 & 98,9 & 773 & 80,8 & 810 & & 1.128 & 54,8 & 1.194 & 51,3 \\
\hline Rincón del Medik & 581 & 86,6 & 813 & 61,7 & 779 & & 973 & 50,0 & 1.033 & 48,6 \\
\hline Castillejos & 549 & 100,0 & 925 & 88,0 & 1.107 & & 4.199 & 87,0 & 4.252 & 86,6 \\
\hline Zeluán & 407 & 88,7 & 378 & 71,5 & 260 & & 194 & 45,1 & 217 & 43,8 \\
\hline Puerto Capaz & 175 & 32,2 & 175 & 10,0 & 102 & & 114 & 14,9 & 122 & 14,4 \\
\hline Monte Arruit & 295 & 88,6 & 319 & 63,7 & 407 & & 485 & 61,1 & 536 & 56,1 \\
\hline Torres de Alcalá & 173 & 49,1 & & & & & & & & \\
\hline Karia de Arqueman & 131 & 47,7 & 50 & 47,6 & 76 & & 60 & 66,7 & 58 & 61,7 \\
\hline Zaio & 175 & 65,1 & 222 & 60,8 & 327 & & 320 & 68,8 & 325 & 66,7 \\
\hline Tiztutin & 120 & 82,8 & & & & & & & & \\
\hline Cabo de Agua & 98 & 90,7 & & & & & & & & \\
\hline Dar-Xaui & 100 & 100,0 & & & & & & & & \\
\hline Fondak & 79 & 100,0 & & & & & & & & \\
\hline Total & 41.660 & 29,7 & 57.616 & 30,4 & 63.085 & & 75.901 & 32,6 & 82.125 & 33,9 \\
\hline \% población urbana & 93,9 & & 92 & & 88 & & 90 & & 90 & \\
\hline Tánger & & & $15.486 *$ & & & & & & & \\
\hline
\end{tabular}

* en noviembre de 1941.

FUENTE: Ministerio de Trabajo. Dirección General de Estadística, Zona de Protectorado y de los territorios de soberanía de España en el Norte de África. Anuario Estadístico.

desfavorable ya que el $41 \%$ de los colonos cultiva menos de 5 ha, y sólo el $13 \%$ tiene explotaciones con más de 100 ha, de las que 7 superan las 500 ha. El 84\% del total de las tierras de los colonos se encuentran en el Quert (región oriental).

Igual conclusión de minifundismo agrario insuficiente en el Protectorado español, se deduce de una relación de propiedades agrícolas de españoles publicada en 1988 con motivo de su expropiación ${ }^{95}$ :

95 B.O.E. de 7 de julio 1988, reproducida en ADERMA, Boletín de la Asociación de Españoles Residentes en Marruecos, $\mathrm{n}^{\circ}$ 35, 31-XII-1988, pp. 6-7. 
Es bien patente la distinta estructura de la propiedad agraria perteneciente a españoles en ambos Protectorados, con una media — según esta muestra - de 19 ha en el norte y de 137 en el sur (el «Marruecos útil»); poseen menos de 25 ha el $79 \%$ de los propietarios en el Norte, contra el $44 \%$ en el Sur. En este «entorno» agrario, la documentación de archivo reitera las referencias a migraciones estacionales (siega, vendimia) de españoles y marroquíes hacia el Protectorado francés de Marruecos así como hacia Argelia ${ }^{96}$.

Asimismo un estudio fechable a principios de los años 1950, señala que las propiedades agrícolas de los europeos en el Marruecos francés suelen ser superiores a 100 ha; los franceses ocupan los cuadros administrativos y económicos, mientras la importante colonia española trabaja como obreros en las ciudades o como gerentes de las granjas ${ }^{97}$.

Por otra parte, según las profesiones que declaran los migrantes españoles con destino o procedentes de Marruecos ${ }^{98}$, los agricultores casi siempre fueron minoría entre 1882 y 1936, mientras entre uno y dos tercios de los migrantes declaran pertenecer al sector «comercio-transportes», los profesionales liberales son entre el 5 y $10 \%$, igual que los industriales-artesanos, aunque estos ofrecen oscilaciones temporales muy acusadas; el grupo «otros», que incluye a los militares, entre 1926 y 1936 oscila entre un cuarto y el $44 \%$ del total. En conjunto, esta distribución porcentual refleja bien la residencia urbana de los españoles en Marruecos.

El Anuario estadístico del Protectorado español de 1955 señala que la escasa industria existente depende de los empresarios españoles. Sobre un total de 1.245 empresas, los españoles poseen 326 ó el 26\%, pero el valor de éstas es el $90 \%$ del total; es decir, la industria propiedad de musulmanes $-72 \%$ de las empresas y $5 \%$ del valor - está referida exclusivamente a la artesanía, extremo confirmado en los comentarios de la documentación española de archivo ${ }^{99}$.

El mismo Anuario de 1955 ofrece una estadística de obreros sindicados en las cuatro ciudades con mayor número de españoles: en Tetuán eran 10.880, en Villa Nador 3.888, en Villa Sanjurjo 1.803 y en Larache 1.116. De un total de 17.687 obreros sindicados, 15.945 eran españoles; su distribución por sectores económicos es:

$\begin{array}{lll}\text { Agrícola y forestal: } & 1.977 \text { obreros, } 11 ' 2 \% \\ \text { Sector secundario: } & 8.514 & \text { id., } 48 \text { ' } 1 \% \\ \text { Sector terciario: } & 4.812 & \text { id., } 27 \text { ' } 1 \% \\ \text { Sin especificar: } & 2.384 & \text { id., } 13 \text { ' } 5 \%\end{array}$

Las ramas de actividad con mayor número de obreros sindicados eran construcción (3.134), transportes (1.665), metalurgia (1.386), hostelería (1.126) y confección (1.119).

Sin embargo, esta distribución de los obreros sindicados parece que no refleja bien el reparto por ramas de actividad del total de los trabajadores españoles, ya que en «pesca y derivados» estaban sindicados 869 trabajadores, mientras que las almadrabas e industrias derivadas de la pesca, según el mismo Anuario, empleaban a 2.599 trabajadores, de los que

96 AGA, Caja AF-M-2.480 (ant. Leg. 4.120). Caja AF-M-2.100.

97 AGA, Caja AF-D-309. El estudio, probable traducción, se titula «Perspectivas marroquíes», 18 pp., sin fecha, ni autor.

98 Datos recogidos en Bonmatí Antón, J.F., Ob. cit., pp. 223-226.

99 En 1942 el Jefe de los Servicios de Estadística en Tetuán afirmaba que la población indígena se dedicaba sólo a la agricultura, excepto los nómadas de las cábilas del sur, que eran ganaderos.

En 1953 (5-XI) el Delegado de Estadística reclamaba que «...aprovechando la próxima rectificación del censo» se debería obtener «la profesión de cada marroquí, teniendo en cuenta que cuando practican varias profesiones deben figurar todas, como ocurre p.e. con los artesanos que practican conjuntamente la agricultura» (AGA, Caja AF-M-2.100). 
1.866 eran españoles; en minería están sidicados 50 trabajadores, pero el total son 3.264, de los que 551 eran españoles. A lo anterior hay que añadir un abultado sector terciario formado por funcionarios y personal dependiente de la Administración (administrativos, docentes, médicos y sanitarios, militares, etc.) que tampoco son incluidos entre los sindicados.

Los extranjeros no españoles eran muy escasos en el Protectorado español, aunque con notable influencia económica, especialmente la de los franceses y alemanes ${ }^{100}$ : en 1955 las estadísticas oficiales indican sólo 419 extranjeros, todos residentes en la ciudades, igual que casi todo el colectivo israelita, cifrado en ese año en 8.217 habitantes ${ }^{101}$. Más de la mitad de estas dos comunidades residían en Tetuán, capital del Protectorado. Si medimos su situación económico-social por la propiedad sobre las industrias, tal como refleja el Anuario, aquélla es asimilable a la de los españoles.

El progreso económico de los israelitas durante el Protectorado queda manifiesto en la documentación española. Así, en la parte antigua de Tetuán — delimitando como tal el perímetro de la ciudad en 1913 - la población censada era de 18.481 habitantes en 1914 y de 37.256 en 1949; en este espacio los israelitas eran 4.250 en 1914 contra sólo 3.346 en 1949; esta disminución es atribuida a su situación económica acomodada que les permitió una migración intraurbana desde la judería a la «ciudad nueva», cuyos edificios, en 1950, eran mayoritariamente propiedad de los israelitas ${ }^{102}$.

\section{Las repatriaciones provocadas por la independencia de Marruecos}

En los años que preceden a la independencia de Marruecos - 1956 - los españoles censados en este territorio ascendían a más de $138.000{ }^{103}$. A diferencia de las otras descolonizaciones españolas en África, la independencia de Marruecos, aunque supuso un proceso de repatriaciones, este fue más escalonado y nunca total ${ }^{104}$.

Los funcionarios de la Administración española fueron, lógicamente, el colectivo más afectado por la repatriación inmediata. En el presupuesto del Protectorado correspondiente a $1954{ }^{105}$, se especifica un total de 9.017 empleos dotados con sueldo ${ }^{106}$, a los que se sumaba un número importante de obreros, especialmente en Obras Públicas (más de 600).

100 Ministerio de Trabajo. Instituto Español de Emigración, Panorama de la emigración española a Marruecos y situación de la colectividad española en este país, Madrid, 1981, 31 pp. mecanografiadas.

101 Presidencia del Gobierno. Instituto Nacional de Estadística, Zona de Protectorado y de los Territorios de soberanía de España en el Norte de África. Último anuario estadístico. 1955.

Según el Censo de Población de 1950 los extranjeros no españoles residentes en el Protectorado eran 443, y los judíos 7.872 .

102 AGA, Caja AF-M-2.400. Esta información fue redactada por el Jefe del Servicio de Estadística, Delegación de la Alta Comisaría. Tetuán (19-1-50).

103 De ellos, 90.939 en el Protectorado español (año 1955), 26.100 en el Protectorado francés (1950-51) y más de 21.500 en la ciudad de Tánger (AGA, Caja AF-D-654).

El posible aumento de españoles en Tánger durante la Segunda Guerra Mundial —en 1941 eran 15.486, mientras en 1961 un artículo de prensa señala la repatriación de más de 21.500 españoles entre 1951 y 1960 — es acorde con los intentos de anexión de la Zona de Tánger a la del Protectorado español, para lo que se intentó multiplicar todo tipo de intereses españoles en esa ciudad (AGA, Caja AF-D-756).

104 Vid. nota 90.

105 AGA, Caja AF-D-333.

106 Su distribución era la siguiente: 59 en Alta Comisaría, 1.011 en Delegación General, 3.210 en Delegación de Asuntos Indígenas, 2.050 en Mejaznía, 739 en Delegación de Obras Públicas, 659 en Delegación de Hacienda, 453 en Delegación de Economía, 694 en Delegación de Educación y Cultura, y 142 en Tribunales españoles de Justicia. 


\begin{tabular}{|crrrrrr|}
\hline \multicolumn{1}{c}{ Años } & Entradas & $\begin{array}{r}\text { Marruecos } \\
\text { Salidas }\end{array}$ & Saldo & Entradas & $\begin{array}{r}\text { Argelia } \\
\text { Salidas }\end{array}$ & Saldo \\
\hline $1882-84$ & 386 & 157 & 229 & 29.580 & 35.898 & -6.318 \\
$1885-89$ & 2.793 & 1.429 & 1.364 & 90.250 & 95.412 & -5.162 \\
$1890-94$ & 4.028 & 3.093 & 935 & 82.388 & 81.740 & 648 \\
$1895-99$ & 3.558 & 3.263 & 295 & 74.634 & 74.368 & 266 \\
$1900-04$ & 5.736 & 5.195 & 541 & 87.917 & 83.945 & 3.972 \\
$1905-09$ & 11.135 & 9.445 & 1.690 & 100.821 & 100.922 & -101 \\
$1910-14$ & 29.161 & 20.790 & 8.371 & 125.009 & 118.663 & 6.346 \\
$1915-19$ & 36.751 & 22.261 & 14.490 & 22.703 & 23.621 & -918 \\
$1920-24$ & 32.509 & 26.801 & 5.708 & 31.006 & 30.197 & 809 \\
$1925-29$ & 26.893 & 29.611 & -2.718 & 23.235 & 26.324 & -3.089 \\
$1930-34$ & 33.905 & 29.205 & 4.700 & 59.354 & 63.574 & -4.220 \\
$1935-39 *$ & 9.028 & 8.693 & 335 & 21.829 & 14.309 & 7.520 \\
$1940-44$ & 47.386 & 33.761 & 13.625 & & & \\
$1945-49$ & 31.877 & 54.515 & -22.638 & $35 * *$ & & \\
$1950-54$ & 59.427 & 85.621 & -26.194 & 4.322 & 6.265 & -1.943 \\
$1955-56$ & 3.344 & 3.178 & 166 & 6.257 & 6.830 & -573 \\
& & & & & & \\
$1882-1956$ & 337.917 & 337.018 & 899 & 759.340 & 762.068 & -2.728 \\
\hline
\end{tabular}

* Años 1935 y 1936.

** Año 1949.

Fuente: Para 1882-1911, Dirección del Instituto Geográfico y Estadístico, Estadística de emigración e inmigración de España; para 1912-1956, Servicio General de Estadística, Estadística del movimiento de buques y pasajeros por mar con el exterior. Este cuadro se ha tomado de la recopilación anual hecha por J.F. Bonmatí Antón, Españoles en el Magreb, siglos XIX-XX, Madrid, Col. MAPFRE, 1992, 269 pp.

De los 9.000 empleos especificados en el Presupuesto, para unos 3.800 se indica su ocupación por marroquíes (de ellos 2.220 son tropa y policía).

El personal español de la Administración del Protectorado fue integrado en la Administración de la metrópoli, tanto nacional como municipal. Entre el 1-IX-1957 y el 28-II-1958, un total de 3.058 expedientes de funcionarios, empleados interinos y obreros solicitaron a Presidencia de Gobierno las indemnizaciones correspondientes ${ }^{107}$. No obstante una parte de los funcionarios españoles permaneció temporalmente en Marruecos, según los acuerdos firmados. Así, documentación oficial de noviembre de 1956 señala que, ante el volumen de la colonia española, era conveniente establecer consulados en las principales ciudades del antiguo Protectorado, que podrían ser atendidos por los antiguos funcionarios españoles que vayan cesando en sus funciones dentro del nuevo estado marroquí ${ }^{108}$.

Las dificultades económicas y de inseguridad padecidas en el nuevo Estado independiente, provocaron una importante repatriación a partir de 1957: «...la población activa 


\begin{tabular}{|lcrc|}
\hline Año & Nacimientos & Defunciones & Matrimonios \\
\hline 1940 & 1.414 & 909 & 521 \\
1941 & 1.462 & 1.215 & 437 \\
1942 & 1.555 & 1.208 & 350 \\
$1943^{*}$ & 1.805 & 1.422 & 472 \\
$1944^{*}$ & 1.716 & 1.034 & 508 \\
$1945^{*}$ & 1.724 & 934 & 425 \\
1946 & 1.553 & 951 & 405 \\
1947 & 1.628 & 842 & 446 \\
1948 & 1.712 & 722 & 470 \\
1949 & 1.721 & 704 & 447 \\
1950 & 1.675 & 674 & 491 \\
1951 & 1.706 & 737 & 467 \\
1952 & 1.876 & 554 & 500 \\
1953 & 1.801 & 539 & 541 \\
1954 & 1.817 & 556 & 627 \\
1955 & 1.934 & 538 & 644 \\
\hline
\end{tabular}

* Tánger incluido.

** Tánger incluido 8 meses.

Fuente: Ministerio de Trabajo. Dirección General de Estadística, Zona de Protectorado y de los territorios de soberanía de España en el Norte de África. Anuario Estadístico. INE, Anuario Estadístico.

española residente en Marruecos, que se mantuvo estabilizada hasta el año 1957, inicia a partir de este año un fuerte descenso como consecuencia de los retornos y repatriaciones a España» ${ }^{109}$. En efecto, un informe del vicepresidente del Banco de Estado de Marruecos señala a 1957 como «año culmen» en los beneficios del Banco, pero desde entonces se inicia un proceso de dificultades debido a la paralización de la economía marroquí, en buena parte como reflejo de la situación política del país ${ }^{110}$.

Esta corriente de repatriación aboca a las Ordenes ministeriales de 16-VII-1962 y de 29-XI-1963 que establecen las normas para la concesión de ayudas para repatriación y emigración de españoles residentes en Marruecos desde antes de la independencia; estas ayudas son tanto a fondo perdido (gastos de documentación, desplazamiento, bolsas de viaje y para establecimiento en España) como en forma de préstamos, y quedan reglamentadas por diversas Resoluciones del Instituto Español de Emigración (18-I-1964, 25-I1964, 1-II-1964, 11-III-1964, 18-III-1964, 20-III-1964, 6-VI-1964, 9-VI-1964). El 4-VI1966 se dicta una nueva Orden que adapta las citadas ayudas al régimen general de repatriación de españoles desde otros países; en el preámbulo de esta orden se indica que «un total de 20.000 españoles» se habían acogido a las primeras ayudas a repatriados de Marruecos.

109 Ministerio de Trabajo, Informe sobre emigración, marzo 1964, mecanografiado.

110 AGA, Caja AF-D-483. 

TES A ESPAÑOLES, SUJETAS A EXPROPIACIÓN. AÑO 1988

\begin{tabular}{|lrrrr|}
\hline & \multicolumn{2}{c}{ En la ex-Zona Norte(a) } & \multicolumn{2}{c|}{ En la ex-Zona Sur(b) } \\
Hectáreas & Propietarios & Hectáreas & Propietarios & Hectáreas \\
\hline 0 '1-5 & 17 & 19 & 10 & 30 \\
5 '1-10 & 3 & 23 & 7 & 46 \\
10 '1-25 & 10 & 150 & 14 & 251 \\
$25,1-50$ & 4 & 145 & 12 & 433 \\
50 '1-100 & 3 & 228 & 6 & 441 \\
100 '1-300 & 1 & 152 & 8 & 1.825 \\
+300 & & & 13 & 6.574 \\
\hline Total & 38 & 717 & 70 & 9.574 \\
\hline
\end{tabular}

(a) Demarcaciones de Tánger, Larache, Alcazarquivir, Tetuán.

(b) Demarcaciones de Rabat, Agadir, Casablanca y Nador y Uxda.

En 1963 se atendieron 1.339 expedientes de repatriación (cada expediente comprende una familia completa), con ayudas de 10'9 millones de pesetas a fondo perdido y 18'7 millones en forma de préstamo ${ }^{111}$. Según las Memorias del Instituto Español de Emigración, en 1965 el «Plan Marruecos» destinó más de 109 millones de pesetas en ayudas para atender 5.189 expedientes de repatriación de Marruecos, en 1967 fueron 87'9 millones de pesetas, mientras en 1968 ya descienden a 19'1 millones y en 1969 a 16'8 millones.

En una serie de artículos que publica J.M. Cerdán en el diario El Alcázar durante mayo de 1961, se indica que entre 1951 y 1960 se marcharon de Tánger 21.500 españoles, además de 7.500 judíos, 1.700 franceses, 926 italianos, 200 suizos, etc., mientras los musulmanes aumentaban en 24.000; con la emigración de los europeos desaparecieron — según el citado articulista - 900 firmas comerciales, bancarias e industriales. Esta evolución de Tánger responde a la caducidad de su administración internacional (8-X1956) e incorporación a Marruecos, en el cuadro del período «transitorio» de vigencia de la Carta Real entre agosto de 1957 y el 19-X-1959.

En marzo de 1970, según el Ministerio de Trabajo de España, residían en Marruecos unos 28.000 «trabajadores» españoles, de los que 7.038 en territorio del antiguo Protectorado español, 12.483 en el ex-Protectorado francés (de los que 9.179 en Casablanca) y 8.299 en Tánger ${ }^{112}$. Las destacadas cifras de las dos últimas ciudades —63\% del total— se explican, en parte, por la inmigración española de carácter político recibida entre 1938 y 1942 (guerra civil española y represiones subsiguientes), en buena parte profesionales liberales, funcionarios y cuadros medios ${ }^{113}$, que buscan en ellas el lugar política y económicamente más apropiado.

111 Ministerio de Trabajo, Informe sobre emigración, marzo 1964, mecanografiado.

112 Ministerio de Trabajo. Instituto Español de Emigración, Panorama de la emigración española a Marruecos y situación de la colectividad española en este país, Madrid, junio de 1981. La distribución de estos trabajadores era: Tetuán 3.978, Larache 2.014, Nador 1.046, Tánger 8.299, Casablanca 9.179, Rabat 2.702, Uxda 309, Agadir 293, e Ifni 9, total 27.829.

113 Memoria anual de la Agregaduría Laboral de la Embajada de España en Marruecos. Año 1983. 
En 1971, también según el Ministerio de Trabajo, el censo «total» de españoles residentes en Marruecos ascendía a 43.498, de los que 8.082 en el ex-Protectorado español, 26.668 en el ex-Protectorado francés (20.500 en Casablanca) y 9.295 en Tánger ${ }^{114}$; más del $68 \%$ se censaban entre Casablanca y Tánger. La comparación de la distribución de «trabajadores» y «población total» española en 1970 y 1971, respectivamente, se revela interesante:

\begin{tabular}{|lcc|}
\hline & \% trabajadores & \% población total \\
\hline En ex-Protectorado español & 25 & 19 \\
En ex-Protectorado francés & 45 & 60 \\
En Tánger & 30 & 21 \\
\hline Total & 100 & 100 \\
\hline
\end{tabular}

Destacan las situaciones opuestas entre las zonas de influencia de Francia y España, en el norte permanece una población española básicamente laboral, mientras en el sur la estructura familiar es mucho más destacada; a parte de una situación económica más atractiva en el antiguo Marruecos francés - Casablanca suma casi la mitad de toda la colonia española-, la diferente composición familiar de los españoles entre el norte y sur de Marruecos también se explica, sin duda, por la herencia de los refugiados de la Guerra civil, establecidos en el entonces Protectorado francés.

La segunda oleada de repatriaciones se produce a partir de 1973, cuando se promulgan (2-III-73) los «Dahires de marroquización» de las actividades de producción, de puestos de trabajo y de nacionalización de tierras propiedad de extranjeros. Entre junio de 1974 y diciembre de 1975 se repatrían hacia España unas 20.000 familias, a las que habría que añadir las que se dirigen a otros puntos de Europa, singularmente hacia Francia ${ }^{115}$.

Para atender esta conflictiva situación se promulgó un nuevo Decreto (7941/1974, de 28 de marzo) sobre medidas de ayuda a los españoles que se repatríen de Marruecos ${ }^{116}$, así como la Orden de 5-IV-1974 por la que se determinan las condiciones para conceder créditos a los repatriados - trabajadores por cuenta propia o propietarios de industrias y comercios- por parte de los bancos Hipotecario de España y de Crédito Industrial. Estos créditos para establecerse en España podrían alcanzar al 100\% de la inversión a realizar, con máximo de 5 millones de pesetas por propietario. Para atender a los propietarios agrícolas repatriados de Marruecos a causa de su expropiación, se dicta la Orden de 30VII-74, entre cuyos auxilios figura la concesión de créditos por el Banco de Crédito Agrícola, destinados únicamente a la adquisición de una explotación agraria, cuya superficie no podría exceder a la poseída en Marruecos ni su producción final agraria ser inferior a 400.000 pesetas; el préstamo podría alcanzar un máximo de 25 millones de pesetas.

En consecuencia a la situación creada en 1973, a principios de 1980 los trabajadores españoles en Marruecos, según los consulados, se habían reducido a $8.094{ }^{117}$, de los que el

114 Ministerio de Trabajo. Instituto Español de Emigración, La emigración en 1971, julio 1972, 150 pp. La distribución de este censo era: Tetuán 4.455, Larache 2.011, Nador 1.616, Tánger 9.295, Casablanca 20.500, Rabat, Kenitra, Fez, Mequinez 4.492, Uxda 733, Agadir 443.

115 Memoria anual de la Agregaduría Laboral de la Embajada de España en Marruecos. Año 1983.

116 Residentes en Marruecos el 2-3-1973 y que no hubiesen recibido ayudas similares con anterioridad.

117 Ministerio de Trabajo. Instituto Español de Emigración, Panorama de la emigración española a Marruecos... op. cit., Madrid 1981. La distribución de los trabajadores era: Larache 441, Nador 79, Rabat 913, Agadir 185, Casablanca 3.811 y Tánger 2.665 (no se indican cifras para Tetuán). 
$80 \%$ se concentran en Casablanca y Tánger. La numerosa colonia española en Casablanca anterior a la marroquización de 1973 (20.500 españoles), en 1986 se ha reducido a unos 2.500 habitantes, en su mayoría personal cualificado ${ }^{118}$.

Durante los años 1980 el censo de españoles residentes en Marruecos se ha mantenido, aunque con tendencia a disminuir lentamente (9.571 residentes en 1983, 8.460 en 1990) dadas la díficil situación económica del país, las restricciones laborales a los extranjeros impuestas por el Gobierno desde 1973 y el envejecimiento de la colonia más antigua, que no suele experimentar renovación ${ }^{119}$.

Las ciudades españolas de Ceuta y Melilla, con crecimiento fulgurante conectado con la ocupación española del Protectorado ${ }^{120}$, al cesar éste en 1956 también fueron residencia —en parte temporal - de numerosas familias marroquíes vinculadas a la Administración española: en 1958 se les entregó, como documento de identidad, una «tarjeta estadística» a todos los varones marroquíes con 16 ó más años de edad, así como a las mujeres cabezas de familia, con un total de 6.799 tarjetas en Ceuta y 7.595 en Melilla; el número de estas tarjetas fue aumentado hasta 1964 (600 en Ceuta, 1.100 en Melilla), aunque en 1965 unas 900 de estas familias ya habían vuelto a Marruecos o emigrado a otros lugares. A esta población marroquí «oficial» en Ceuta y Melilla, hay que añadir en los años que siguen a la independencia de Marruecos, los marroquíes ya residentes en ambas ciudades antes de 1956 - con frecuencia familias de soldados en el ejército español—, y una considerable colonia de no controlados, pero estimada en una cifra similar a los poseedores de tarjetas estadísticas ${ }^{121}$. En el resto del territorio español parece que no hubo inmigración significativa de marroquíes con motivo de la independencia de su país ${ }^{122}$.

118 Agregaduría Laboral de la Embajada de España en Marruecos, Memoria de actividades, 1986 (mecanografiado).

119 Memoria anual de la Agregaduría Laboral de la Embajada de España en Marruecos. Año 1983. Los 9.784 españoles residentes en Marruecos en 1983 (según los consulados) presentan la siguiente distribución: 2.869 en Tetuán, 693 en Larache, 272 en Nador, 877 en Rabat, 170 en Agadir, 3.588 en Casablanca y 2.869 en Tánger. Son activos el $31 \%$, y de estos casi un tercio por cuenta propia (536 comerciantes e industriales, 428 profesionales); entre los que trabajan por cuenta ajena los más numerosos se dedican a la industria (782), seguidos por funcionarios y profesores (489), y con menor importancia los dedicados a servicios (249), comercio (183) y agricultura y pesca (174); Casablanca concentra el $70 \%$ de los españoles dedicados a profesiones liberales.

120 Roda Jiménez, R. de, «Estructura y evolución de la población de Marruecos», s.a., 29 pp. (utiliza cifras de población del censo de 1940). Melilla censaba 8.956 habitantes en 1900, 39.852 en 1910, 50.170 en 1920 y 62.614 en 1930. Ceuta tenía 13.269 en 1900, 23.907 habitantes en 1910, 35.219 en 1920 y 50.614 en 1930.

121 AGA, Caja AF-D-1.833.

122 González Yanci, M. P., «Inmigrantes marroquíes en España. Un movimiento en alza oculto en la clandestinidad», III Jornadas de población española, Dpto. de Geografía de la Universidad de Málaga, 1991, pp. $77-84$. 


\section{Fuentes y Bibliografía}

- Archivo General de la Administración (Alcalá de Henares, Madrid). Conserva la documentación generada por la Administración española en África, agrupada en la denominada «Sección de África»; los fondos ocupan unos 3.700 m.l. de estantería.

- Biblioteca Nacional (Madrid). En 1966 creó una «Sección de África» en la que se integraron diversas bibliotecas particulares donadas a la institución, así como la perteneciente a la antigua Dirección General de Marruecos y Colonias*. Esta Sección desaparece en 1986, integrándose sus fondos (1989) en los distintos depósitos de la Biblioteca. En 1988 el tema africano incluía 21.418 monografías, unos 30.000 folletos y 634 misceláneas, además de manuscritos, fondos gráficos, etc. No obstante, sobre el tema de la presente investigación, la bibliografía parece ser muy escasa.

- Instituto Español de Emigración, desde 12-X-1991 Dirección General de Migraciones (Madrid). Posee biblioteca especializada.

- Comisaría de España en Marruecos, Censo general de la población y de edificaciones y viviendas de la Zona de Protectorado. Manual de Instrucciones, Ceuta (1951), 113 pp.

- Delegación de Asuntos Indígenas. Servicio de Intervenciones, Anuario, Tetuán, 1955, 505 pp. mecanografiadas (Biblioteca Nacional, Madrid).

- Dirección General de Marruecos y Colonias. Instituto de Estudios Africanos. Gobierno General de los Territorios de Guinea, Resúmenes estadísticos del Censo general de población del Gobierno General de los Territorios españoles del Golfo de Guinea al 31 de diciembre de 1950, Madrid, 1952, 157 pp. Trata separadamente a la población indígena y a la europea.

- Dirección General de Marruecos y Colonias. Sección de Estadística de la Delegación de Trabajo del Gobierno General de los Territorios españoles del Golfo de Guinea. Serie de volúmenes estadísticos iniciada en 1941; los volumenes siguientes abarcan dos años; constan de más de 200 páginas cada uno. Esta serie la inició el Negociado de Estadística del Gobierno General de Guinea Ecuatorial, cuya actividad comenzó en 1941.

- Dirección General de Plazas y Provincias Africanas e Instituto de Estudios Africanos, Resumen Estadístico del África Española. El primer volumen (578 pp.) fue publicado en 1954 por la Dirección General de Marruecos y Colonias y el Instituto de Estudios Africanos, los dos siguientes volúmenes cubren períodos trienales (1953-55; 1956-58) y bienales los que siguen, hasta 1965-66, último número de la serie, que se interrumpe por la independencia de Guinea en 1968 y la retrocesión de Ifni a Marruecos en 1969.

- Dirección General de Promoción de Sáhara e Instituto de Estudios Africanos, Resumen Estadístico del Sáhara Español (Año 1969), C.S.I.C., Madrid, 1970, 31 pp.

- Dirección General de Plazas y Provincias Africanas e Instituto de Estudios Africanos, La Región Ecuatorial Española al día, Madrid, C.S.I.C., 1963, 44 pp.

- Gobierno General del Sáhara, Censo de población, 1974, 151 pp. El censo está referido a 31-XI1974. La información fue recogida por un equipo de 30 nativos bilingües (en su mayoría estudiantes), que dispusieron de 10 vehículos Land Rover con sus conductores, así como de un helicóptero para acceder a los lugares más difíciles; la dirección fue de un equipo de funcionarios del Sáhara, supervisados por personal del INE. A diferencia del censo de 1967, la publicación del de 1974 no recoge a la población europea.

- Gobierno General de la Provincia de Sáhara. Secretaría General, Provincia de Sáhara. Censo de Población, 59 pp. El censo está referido a 31-XII-1967. Consta de dos partes, la primera se dedica a la población nativa (pp. 7-42) y la segunda a la población europea (pp. 45-59).

- Gouvernement Cherifien. Service Central des Statistiques, Annuaire Statistique de la zone française du Maroc. 1950-1951, Rabat, 470 pp.

- Instituto Español de Estadística, Anuario estadístico de España.

* La Dirección General de Marruecos y Colonias fue creada en 1925 para coordinar la acción del Estado español en África, fue transformada en D.G. de Plazas y Provincias Africanas en 1956 (independencia de Marruecos), y en D.G. de Promoción del Sáhara en 1969, tras la descolonización de Guinea (1968) y de Ifni (1969). 
- Marruecos. Protectorado Español. Delegación General. Servicio de Estadística, Censo de Población y Estadística de Edificaciones y Viviendas. Año 1950. Resúmenes, 15 pp.

- Ministerio de Trabajo. Dirección General de Estadística, Zona de Protectorado y de los territorios de soberanía de España en el norte de África. Anuario Estadístico. Esta colección de anuarios, en los que después aparecería como organismo editor la Presidencia del Gobierno, Instituto Nacional de Estadística, cubre los años 1941 a 1955, ya que la independencia de este territorio fue firmada el 7 de abril de 1956. La información que contienen es relativamente amplia, con alternancia de cuadros estadísticos y comentarios; el primer tomo tiene 319 páginas, mientras el último llega a 829 páginas. La publicación es anual, excepto 1949-50 y 1952-53.

- Royaume du Maroc. Ministère de l'Economie nationale, Annuaire statistique du Maroc (ex-zone Sud), 1955-1956, Rabat, Service Central des Statistiques, 468 pp.

- Bonmatí Antón, J.F., Españoles en el Magreb siglos XIX y XX, Madrid, Col. MAPFRE, 1992, $269 \mathrm{pp}$.

- Diego Aguirre, J.R., Historia del Sáhara Español. La verdad de una traición, Madrid, Kaydeda ed., 1988,879 pp.

- García Figueras, T., Economía social de Marruecos, Madrid, Inst. Est. Africanos, C.S.I.C., 1950, 3 vols.

- García Figueras, T., España y su Protectorado de Marruecos (1912-1956), Madrid, Instituto de Estudios Africanos, C.S.I.C., 1957, 356 pp.

- Presidencia del Gobierno. Secretaría General Técnica, La descolonización del Sáhara, Madrid, 1975, 61 pp.

- Mensua Fernández, S., Bibliografía geográfica de Marruecos Español y Zona Internacional de Tanger, Zaragoza, Departamento de Geografía Aplicada del Instituto Elcano, C.S.I.C., 1956, 149 pp.

- Morales Lezcano, V., España y el norte de África: el Protectorado en Marruecos (1912-1956), Madrid, Universidad Nacional de Educación a Distancia, 1986, $2^{\circ}$ ed.

- Noin, D., La population rurale du Maroc, Publications de l'Université de Rouen, PUF, 1970, 2 vols.

- Roda Jiménez, R. de, «Estructura y evolución de la población de Marruecos», Rev. Inter. de Sociología, separata s.a., 29 pp. 